\title{
Spatial and temporal dynamics of gas-related processes in the Sea of Marmara monitored with ocean bottom seismometers
}

\author{
Eve Tsang-Hin-Sun, Evangelia Batsi, Frauke Klingelhoefer and Louis Géli \\ Ifremer, Marine Geosciences, CS 10070-29280 Plouzané, France.E-mail: eve.tsang.hin.sun@ifremer.fr
}

Accepted 2018 December 19. Received 2018 December 10; in original form 2018 July 15

\begin{abstract}
SUMMAR Y
In the Sea of Marmara, areas of gas seepage or cold seeps are tightly related to the faults system and understanding the spatial and temporal dynamics in gas-related processes is crucial for geohazard mitigation. Although acoustic surveys proved to be efficient in detecting and locating cold seeps, temporal variability or trends in the gas-related processes are still poorly understood. Two arrays of 10 ocean bottom seismometers were deployed in the western part of the Sea of Marmara in 2011 and 2014, respectively. In addition to the local seismic events, the instruments recorded a large number of short duration events and long-lasting tremors. Short duration events are impulsive signals with duration $<1 \mathrm{~s}$, amplitude well above the noise level and a frequency spectrum with one or two narrow peaks. They are not correlated from one site to another, suggesting a very local source. Tremors consist of sequences of clustered impulsive signals lasting for minutes to more than an hour with a multipeak frequency spectrum. Based on evidence of known seepage and by analogy with volcanic and hydrothermal models, we suggest that short duration events and tremors are associated with gas migration and seepage. There is a relationship between tremors associated with gas emission and the local seismicity, although not systematic. Rather than triggering gas migration out of the seabed, locally strong earthquakes act as catalysts when gas is already present or gas emission is already initiated.
\end{abstract}

Key words: Gas and hydrate systems; Spatial analysis; Time-series analysis; Earthquake source observations; Seismicity and tectonics.

\section{INTRODUCTION}

The Sea of Marmara (SoM; Fig. 1) is the submerged and only segment of the North Anatolian Fault that has not yet ruptured into a strong earthquake $(M>7)$ since the past century. It thus represents a critical seismic hazard in the years to come, especially for the Istanbul megalopolis. Recent studies, however, argue that part of the segment (the Istanbul-Silivri section) is continuously creeping (Ergintav et al. 2014; Bohnhoff et al. 2017), whereas the Princes' Islands section might be locked (Bohnhoff et al. 2013). Moreover, numerous gas seeps have been observed and linked to the tectonic regime in the SoM (Dupré et al. 2015). Gas and fluids sampled in the western SoM have a predominant thermogenic origin, with also a contribution of biogenic methane (Bourry et al. 2009; Ruffine et al. 2012). Whereas the active faults and fractures network provides conduits for gas migration in tectonically active regions, aseismic sections of the SoM, such as the Istanbul-Silivri and Princes' Islands segments, are lacking in gas emissions, suggesting a relationship between tectonic ground motion and gas (Dupré et al. 2015; Géli et al. 2018). In this view, understanding the spatial and temporal pattern in the gas distribution and the mechanisms of gas emission triggering is crucial for geohazard mitigation.
Acoustic techniques, such as multibeam echo sounder or bottom Bubble Observatory (BOB) proved to be efficient in detecting gas emissions in the water column and locating cold seeps on the seafloor worldwide (e.g. Schneider von Deimling et al. 2007; Greinert 2008), including in the SoM (Geli et al. 2008; Bayracki et al. 2014; Dupré et al. 2015). Yet, they rarely inform about temporal variability in the gas-related processes at the basin scale. In hydrothermal or active gas seeping areas, ocean bottom seismometers (OBS) commonly record non earthquake signals, such as short duration events (SDE) and long-lasting tremors, in addition to the local seismic events. In the Galicia margin, Diaz et al. (2007) reported abundant SDEs together with harmonic tremors and, by analogy with volcanic active areas, concluded that they were related to the vibration of fluid-filled cracks in the sedimentary basin. The same hypothesis was proposed to explain the high number of SDEs at the Juan de Fuca Ridge (Sohn et al. 1995) or in the SoM (Tary et al. 2012). In the Taiwan Margin, long-lasting tremors and SDEs were well correlated with gas emission, as both occurred during the same phase of the diurnal tides and with comparable intensity (Hsu et al. 2013). Finally, many SDEs were associated with gas migration and seepage on the Svalbard Margin, as they occur near cold seeps and together with bottom temperature anomalies (Franek 


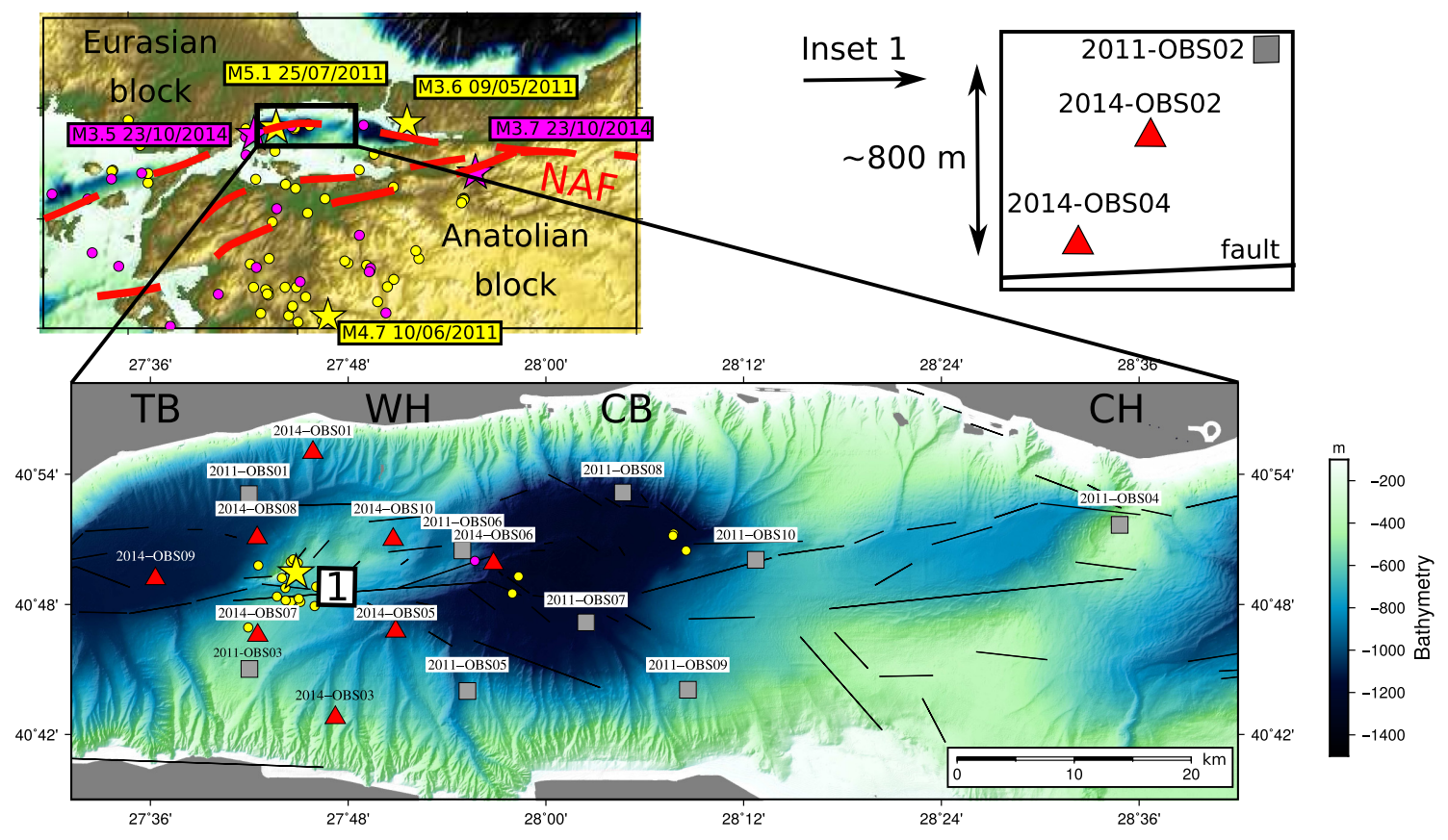

Legend

$\square$ OBS 2011

$\triangle$ OBS 2014

2014-OBS01 OBS active

2014-OBS03 OBS dysfunctionning
- ISC seismicity 2011

- ISC seismicity 2014

Earthquakes mentionned in the text

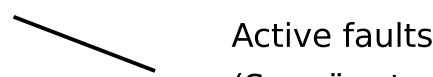

(Sengör et al., 2005)

Figure 1. Location of the Sea of Marmara (SoM) along the North Anatolian Fault (NAF; in red), that separates the Eurasian and Anatolian plates. The black box indicates the study area within the SoM. OBSs were deployed in the western SoM in 2011 (grey square) and on Western High in 2014 (red triangles). The regional earthquakes, extracted from the ISC catalogue, occurring during both experiments are indicated as yellow and magenta circles. The stars are the strongest earthquakes, mentioned in the text. The white square, labelled 1, is sketched on inset 1 since several instruments were deployed on a small area. TB, Tekirdag Basin; WH, Western High; CB, Central Basin, CH, Central High.

et al. 2017). In all above cases, there is a clear relationship between the atypical seismic signals and fluid migration. Multidisciplinary approaches in the SoM also connected SDEs to acoustic gas emission (Bayrakci et al. 2014) or peaks in the methane concentration (Embriaco et al. 2014). Even though the relationship between fluidrelated processes in the sediments and atypical SDEs/tremors has been well established, few studies rely on networks of OBSs and continuous observations.

This paper presents observations of SDEs and long-lasting tremors recorded by two different arrays of OBSs in May-July 2011 and October-November 2014 in the western SoM (Fig. 1), discusses the spatial and temporal patterns in the associated gasrelated processes and examines the relationship between the local seismicity and gas migration triggering.

\section{OBS DATA PROCESSING}

\subsection{Data description}

This study is based on the analysis of two arrays of OBSs, hereafter referred to as '2011' and '2014' arrays and '2011-OBS01', for instance, designates the OBS01 of the 2011 array, etc. (Fig. 1). Both arrays comprise 10 autonomous, four components (one vertical, two non-oriented horizontal and a hydrophone), short-period $(4.5 \mathrm{~Hz})$ OBSs from Ifremer, all recording at a rate of $8 \mathrm{~ms}(125 \mathrm{~Hz})$. The first array was deployed over a $20 * 75 \mathrm{~km}^{2}$ area from the Western High to the Central High, from 15/04/2011 to 31/07/2011, while the second was deployed at a smaller scale $\left(20 * 20 \mathrm{~km}^{2}\right)$ on and around the Western High from 19/10/2014 to 14/11/2014 (Fig. 1). Out of the 20 OBSs, 4 did not function properly and were excluded from the analysis (2011: OBS02 stopped after a few days, OBS03 was corrupted by electronic periodic glitches; 2014: OBS02 stopped after $2 \mathrm{~d}$, OBS03 and OBS09 were corrupted by electronic periodic glitches).

Local and regional earthquakes were extracted from the reviewed seismicity catalogue of the International Seismological Centre (http://www.isc.ac.uk) and compared to the seismic recordings. Most of the events could be clearly identified on the seismograms allowing some earthquakes to be relocated (e.g. Batsi et al. 2018). No particular site effect was noted, when comparing the amplitudes of a given earthquake on the network (Fig. 2). A high noise level is usually observed on the hydrophone recordings, due to the intense ship traffic and the sea-state but most of the earthquakes are still visible on the hydrophone data. In addition to earthquakes, a large 


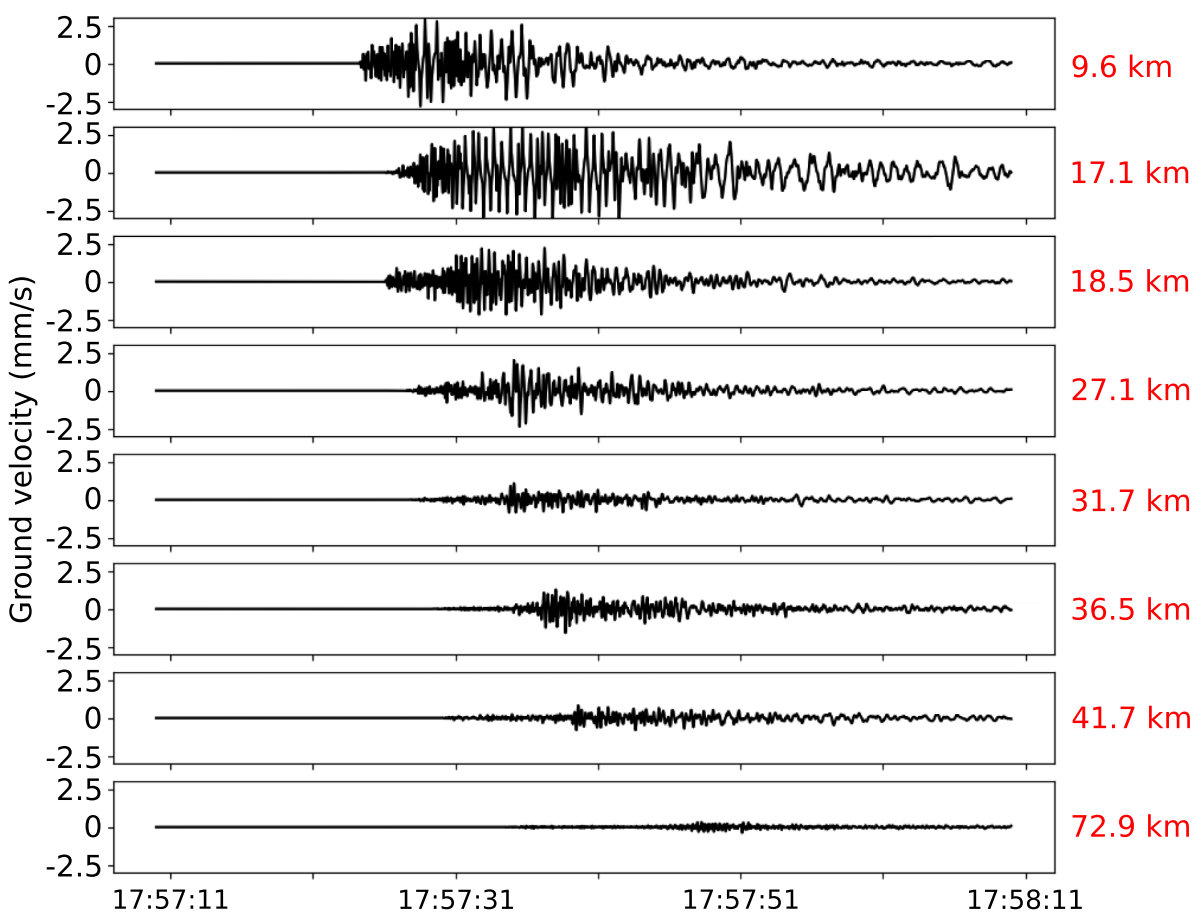

Figure 2. Seismic recordings of the $M_{\mathrm{w}} 5.1$ earthquake on 25/07/2011 over the whole network of OBSs. Seismograms of the vertical component are detrended and bandpassed filtered in the $1-5 \mathrm{~Hz}$ frequency range. The seismic traces are sorted from top to bottom according to the epicentral distance. The ground velocity is deduced after applying the instrumental sensitivity provided by the manufacturer.

number of atypical signals, not correlated between the different instruments, were also observed.

They can be classified in two types: individual SDEs (Fig. 3) and long-lasting tremors (Figs 4 and 5). Both types of signal are not visible on the hydrophones, except for a few SDEs, indicating a poor coupling between the SDE sources and the water column. SDEs generally consist of a single and short $(<1 \mathrm{~s})$ high-frequency wave train (eventually followed by lower frequency oscillations), a frequency spectrum with one or two peaks and a wide range of amplitudes, well above the noise level (Fig. 3). Tremors consist of clusters of hundreds of SDEs within the $10-50 \mathrm{~Hz}$ frequency band, with amplitude well above the noise level and lasting several minutes to more than an hour (Figs 4 and 5). The term tremor might be confusing, since used to designate volcanic events, slow slip events associated with subduction zones or any unusual nonearthquake seismic signal persistent in time. Here we use the term tremor in opposition to SDEs and for consistency with the cited literature.

\subsection{SDE and tremor detection}

Short duration events were automatically detected by applying a recursive short-term average/long-term average (STA/LTA) algorithm, provided by the Python-based ObsPy toolbox (Beyreuther et al. 2010), to the whole detrended, unfiltered time-series. The STA/LTA algorithm continuously evaluates the short-to-long-term ratio in the seismic power and proved to be particularly efficient in detecting weak signals at the same time as limiting an excessive number of false triggers (e.g. Allen 1982; Withers et al. 1998). Adequate detection parameters, such as the length of short and long time windows and trigger/detrigger threshold levels, were selected after a careful analysis of different parameter sets and tested on a randomly chosen 1-hr data sample; triggers were then visually checked and compared to the manually picked SDEs in that window. The optimal parameters are those giving the maximum number of events at the same time as none false trigger (background noise), electronic glitch or aftershock (Table 1). Only events lasting less than $1 \mathrm{~s}$ were selected in order to match the SDEs definition and to discriminate them from aftershocks. Visual inspection of known aftershocks sequences revealed no bias in the SDEs detection.

To ensure the homogeneity of the detection level over the whole network, the signal-to-noise ratio (SNR) was computed for all events and compared at each station (Fig. 6). The SNR of a given event is defined as $S N R=\frac{R M S(F[S])}{R M S(F[N])}$ where $R M S$ is the root mean square, $F[S]$ and $F[N]$ are data samples of duration $S$ and $N$, respectively. Here $S$ is a $0.5 \mathrm{~s}$ window centred on the maximum of amplitude of a SDE and $N$ is a $2 \mathrm{~s}$ window of the lowest level of noise, extracted from the $60 \mathrm{~s}$ preceding the SDE arrival. The SNR distributions (median and extreme values) are very similar at all sites (Fig. 6), indicating that the sources of SDE are homogeneous in amplitude at all site. The level of detection of events is thus considered homogeneous for each network of OBSs.

Tremors are considered as a sequence of SDEs during the automatic detection procedure. To distinguish them from individual SDEs, hierarchical clustering was applied to the catalogue of SDEs, for each OBS. The method uses the single linkage clustering (SLC) algorithm (Gower \& Ross 1969) to relate events based on their time of occurrence. Two events, $e_{i}$ and $e_{j}$, belongs to the same cluster at the clustering level $d$ if and only if there is a link of value less or equal to $d$ connecting them; the clustering level $d$ is empirically determined. The analysis was limited to a subset of events occurring less than $10 \mathrm{~s}$ from each other and the interevent time was used to chain the elements. The threshold value linking the elements into a cluster was arbitrarily set to $0.8 * \mathrm{D}$ where $\mathrm{D}$ is the median of 

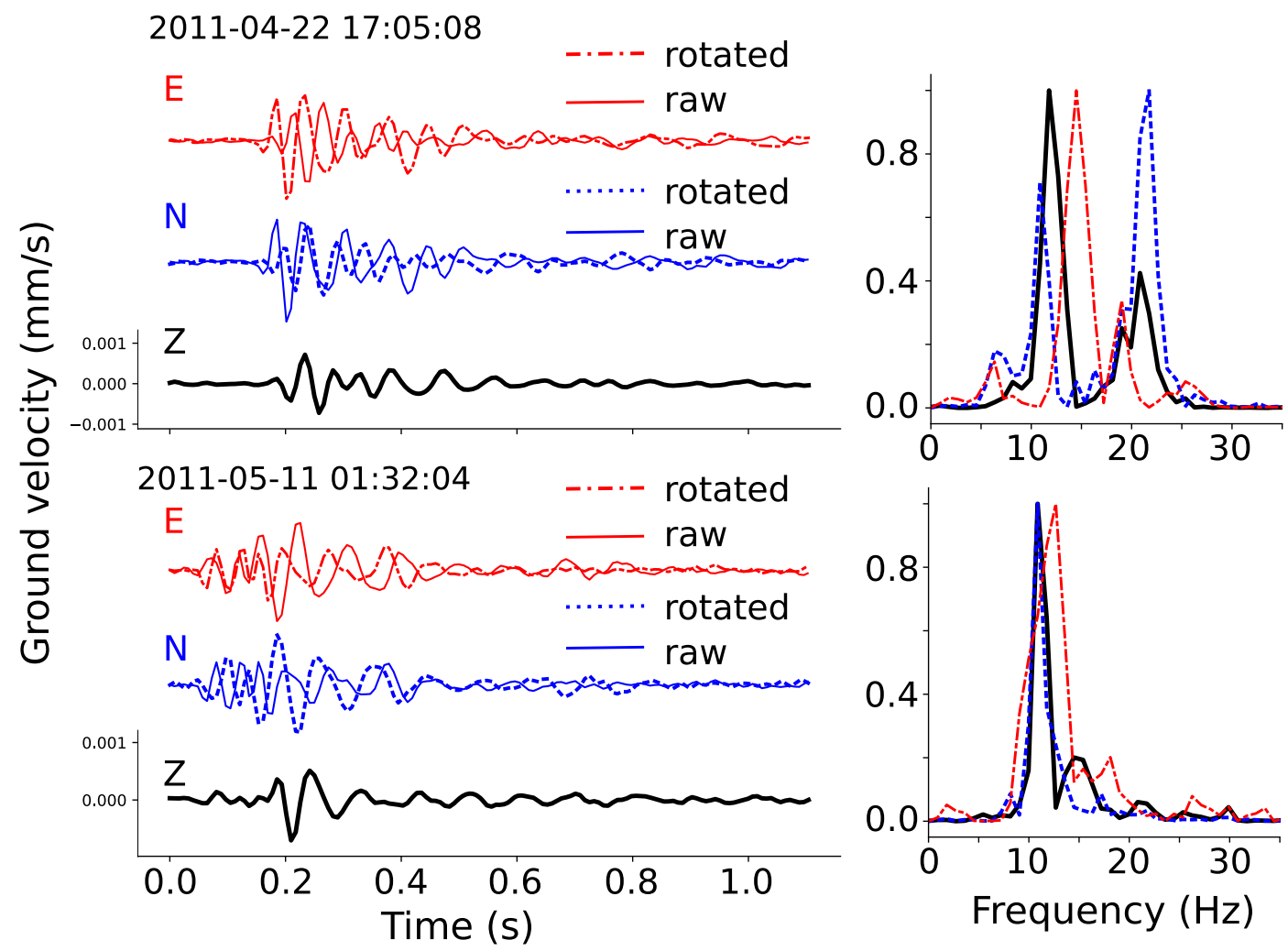

Figure 3. Left-hand panels: two examples of typical SDEs recorded on the geophones of 2011-OBS01. Dashed and dotted lines are the re-oriented seismograms of the $\mathrm{E}$ and $\mathrm{N}$ horizontal components, respectively, while thin solid lines are the misoriented seismograms. For each event, the ground velocity scale is indicated on the vertical component and similar for horizontal components. Right-hand panels: normalized spectrum of each seismogram, computed with 256 DFT points.

all links. Clusters of more than 10 events were then considered as tremors and start and end time of the tremors were defined accordingly. This method allow the detection of the largest tremors but certainly not all tremors.

\subsection{Backazimuth determination}

The mis-orientation of the geophone horizontal components, H1 and $\mathrm{H} 2$, with respect to the geographic north, was estimated through the SNR-weighted-multi-events method developed by Niu \& Li (2011). Although polarization of $P$ waves (Wang et al. 2016), surface waves (Stachnik et al. 2012; Scholz et al. 2017; Doran \& Laske 2017) or ambient noise (Zha et al. 2013) have proved to be efficient for orienting OBSs, the technique of Niu \& Li (2011) was preferred since it is applicable to short duration experiments (a few months) and do no require the precise determination of the $P$-wave vertical polarity. As a matter of fact, for many regional earthquakes $(<200 \mathrm{~km}$; Fig. 1), the $P$-wave first arrival was emergent and thus difficult to pick.

For a given orientation $\phi$, ranging from $0^{\circ}$ to $180^{\circ}$, the horizontal components $\mathrm{H} 1$ and $\mathrm{H} 2$ are first rotated into the assumed radial and transverse components according to the theoretical backazimuth $\theta_{\mathrm{i}}$ of the known $i$ th earthquake $(i=1, \mathrm{M})$. The weighted average of the $P$-wave energy in the transverse component over the $M$ earthquakes is then,

$E_{T}(\phi)=\frac{\sum_{i=1}^{M} w_{i} E_{T}^{i}(\phi)}{\sum_{i=1}^{M} w_{i}}$, where $E_{T}^{i}(\phi)$ is the $P$-wave energy in the transverse component of the $i$ th earthquake (computed within a $2 \mathrm{~s}$ window after the first $P$ wave arrival); $w_{\mathrm{i}}$ is a weight depending on the SNR of the horizontal components, $w_{i}=0.5 *\left(S N R_{i, S H N}+S N R_{i, S H E}\right)$, with SNR computed as previously detailed. The best $\phi$ is obtained when $E_{T}(\phi)$ reaches a minimum and the $180^{\circ}$ ambiguity is solved for a positive correlation between the vertical and radial components. 44 and 37 earthquakes were used to estimate the orientation of the OBSs for the 2011 and 2014 arrays, respectively. Earthquakes were selected to cover the widest azimuthal range, although some directions are not represented (Fig. 1). The uncertainty on $\phi$ can be statistically estimated since $E_{T}^{\min }$ is supposed to follow a $\chi^{2}$ distribution, thus $\frac{E_{T}}{E_{T}^{\min }}$ follows a F-distribution (Niu \& Li 2011). The 95 per cent confidence interval for $\phi$ is then estimated as,

$\frac{E_{T}(\phi)}{E_{T}^{\min }} \leqslant 1+\frac{k}{n-k} f_{k, n-k}(0.95)$,

where $k=1, n$ is taken as 1 degree of freedom per second (2 in our case) and $f$ is the inverse of the F-distribution. Uncertainties in the orientation estimates range from $2^{\circ}$ to $16.5^{\circ}$ at the 95 per cent confidence interval in 2011 and between $2.5^{\circ}$ to $20^{\circ}$ in 2014, although they might be somehow underestimated for noisy data.

The direction of the SDE sources (backazimuth) was then computed based on the estimated orientation of the horizontal components and the particle motion in the horizontal plane. As the SDE arrivals are usually emergent on the vertical component recordings, no vertical polarity could be determined and a $180^{\circ}$ ambiguity remains in the estimated backazimuths. The uncertainty of the absolute measurement of the backazimuth is difficult to assess 
(a)

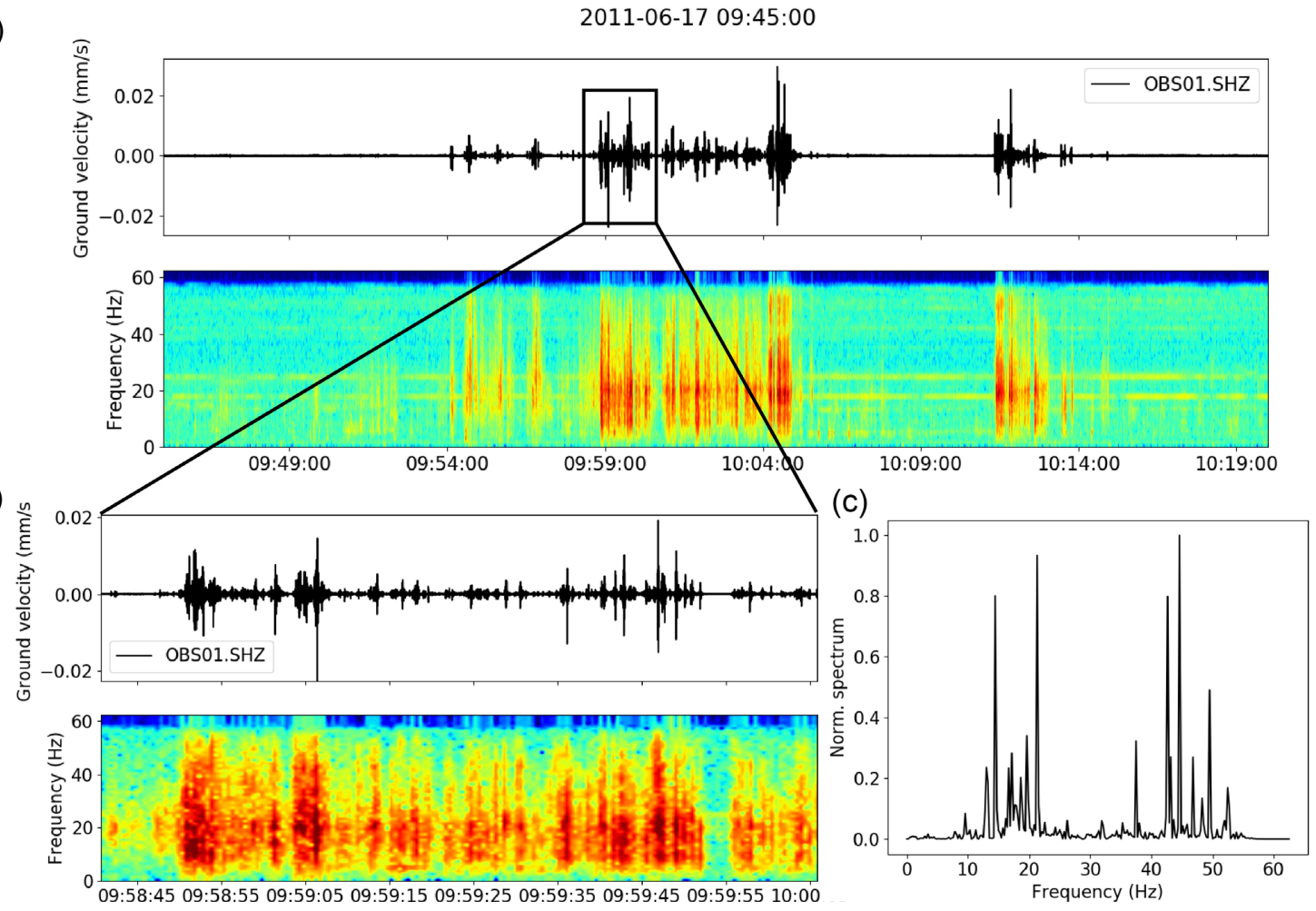

Figure 4. Example of a long-lasting tremor of type 1 recorded on 2011-OBS01, recorded on the vertical component of the geophones. (a) Seismogram, detrended, unfiltered, starting on 17/06/2011 09:45:00 (UTC) and corresponding normalized spectrogram, representing the distribution of the power in time and frequency. The spectrogram is computed for 512-samples segments and 90 per cent overlap. (b) a close up on a 2 min data sample; (c) the normalized frequency spectrum for the signal on (b).

since it depends on the mis-orientation uncertainty of the OBS, the SNR of the individual SDE and the uncertainty in the polarization analysis.

\section{SHORT DURATION EVENTS}

A large number of short and impulsive signals were recorded on both arrays of OBS. They generally consist of signals with: (i) short duration ( $<1 \mathrm{~s})$; (ii) amplitudes above the noise level; (iii) a frequency spectrum with one to several narrow peaks and dominant frequency at $17 \mathrm{~Hz}$ on average but varying between 4 and $30 \mathrm{~Hz}$; (iv) a single wave train eventually followed by a lower frequency coda (Fig. 3). As already noticed by other studies (Diaz et al. 2007; Franek et al. 2017), SDEs can be classified according to their frequency content or waveform. Even though we observed some common and possibly discriminating parameters in the spectrum and waveform of all SDEs, we did not perform such an analysis because of the size of our data set (more than 40000 events at 2011-OBS1, for instance) but also because such categorization does not necessarily resolve the nature of the SDE source. Generally, the spectral analysis of SDEs shows a complex frequency content, probably resulting from the combination of randomly vibrating sources.

The average daily rate of SDEs is highly variable across the SoM, with regional contrasts. To further investigate these possible regional trends, the temporal distributions of SDEs were cross-correlated for both 2011 and 2014 networks (Fig. 7). A high level of SDE is observed in the Central High (2011-OBS04; Figs 7 and 8). Although there are variations in the event rate, they are not correlated with other sites, suggesting independent source excitation in the western SoM. In the Central Basin, where 6 OBSs were deployed in 2011, peaks in the daily rate of SDEs seem better correlated $(R=0.7-$ 0.8; Figs 7 and 8). Apart from this temporal pattern, the average number of SDE per day seems to vary across the basin and generally decreases with increasing depth (Fig. 7), suggesting that the height of the water column plays a role in the SDE generation. On the Western High, the highest rate of activity in 2011 is observed at 2011-OBS01 (Fig. 7), where the number of SDE is generally high and sharply increases during the last days of the experiment (Fig. 8). In 2014, 2014-OBS08 is the most active site and is located just a few kilometres from the previous 2011-OBS01 (Fig. 7). The other sites on the Western High have low rates of SDE, except for 2014OBS01, located north of the High (Figs 7 and 9). Contrary to the Central Basin, there is no relationship between the average daily rate of SDE and the deployment depth, suggesting the existence of local effects (Fig. 7).

Backazimuths of the individual SDEs are generally scattered in all directions, suggesting randomly distributed sources (Fig. 10). At some sites, swarms of SDEs focused in a given direction, suggesting a stable source related to the local stress or pressure fields. In addition, this direction can be in good agreement with the tremors one, as typically observed at 2014-OBS08 (Fig. 10b). At 2011-OBS01, individual SDEs are scattered in all directions until the 20/07/2011, although with a preferential direction around $80^{\circ}$ (Fig. 10a). On $21 / 07 / 2011$, this main source direction abruptly shifts to $\sim 150^{\circ}$ and the $80^{\circ}$ source appears inactive. On $25 / 07 / 2011$, simultaneously to a general increase in the number of SDEs, the $150^{\circ}$ source is intensely activated along with other scattered sources. 
(a)

(b)

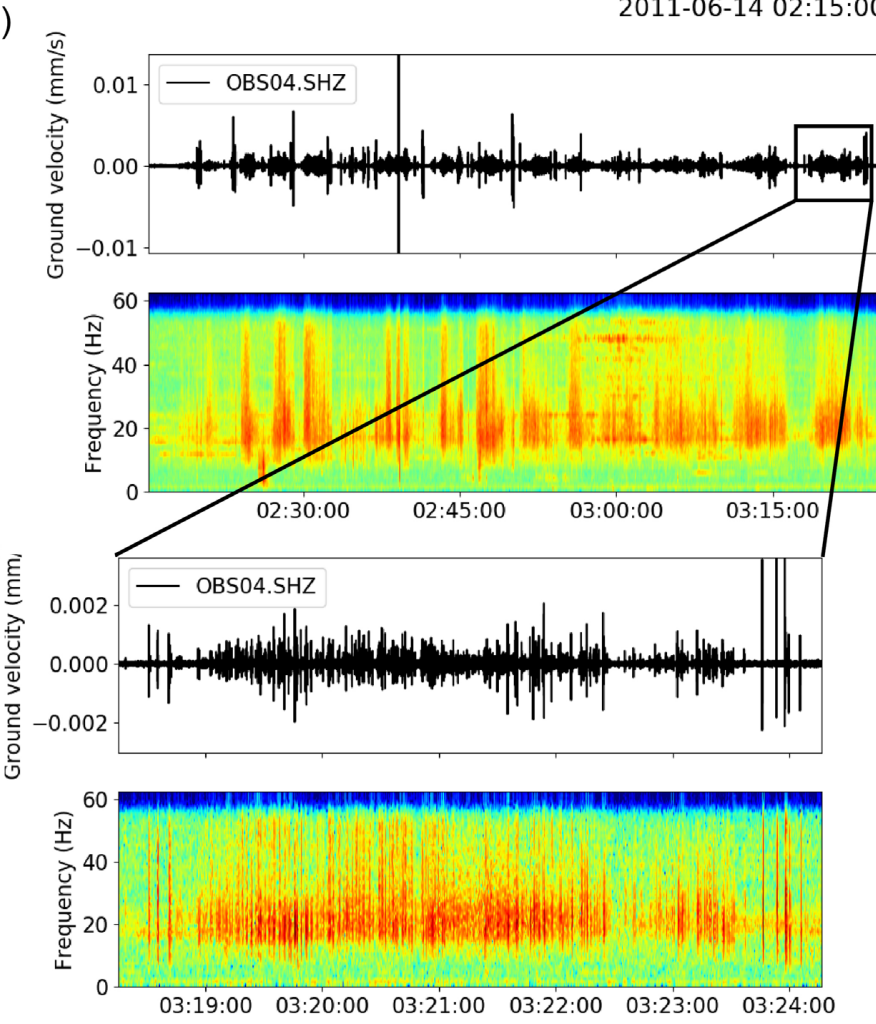

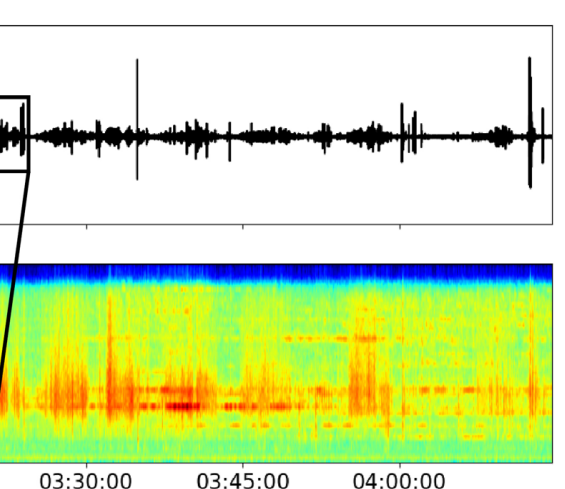

(c)

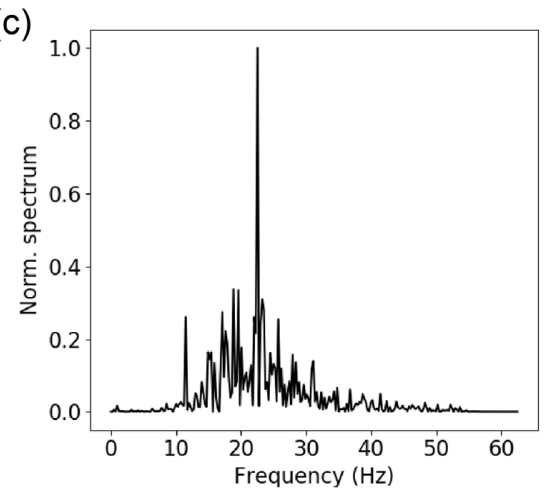

Figure 5. Example of a long-lasting tremor of type 2 recorded on 2011-OBS04 only, recorded on the vertical component of the geophones. (a) Seismogram, detrended, unfiltered, starting on 17/06/2011 09:45:00 (UTC) and corresponding normalized spectrogram, representing the distribution of the power in time and frequency. The spectrogram is computed for 512-samples segments and 90 per cent overlap. (b) a close up on a 5 min data sample; (c) the normalized frequency spectrum for the signal on (b).

Table 1. Detection parameters used in the STA/LTA algorithm for both arrays. STA and LTA are the length of the short- and long-time windows, pre-event and post-event times are buffers eventually added before and after the trigger section.

\begin{tabular}{lc}
\hline STA (s) & 0.35 \\
LTA (s) & 7 \\
Trigger on & 8 \\
Trigger off & 3 \\
Pre-event time (s) & 0.1 \\
Post-event time (s) & 0 \\
Maximum duration of the event (s) & 1 \\
\hline
\end{tabular}

\section{TREMORS}

Two types of tremors were identified in the seismic recordings. Tremors of type 1 typically consist of several clusters of impulsive wave trains, sometimes overlapping each other, with variable amplitudes and lasting some minutes to hours (Fig. 4). The frequency spectrum of a given cluster has several narrow peaks in the $10-50 \mathrm{~Hz}$ range and a dominant high frequency peak, generally above $17 \mathrm{~Hz}$ (Fig. 4). Tremors of type 2 were recorded at 2011OBS04 only and resemble some volcanic tremors (Konstantinou \& Schlindwein 2003). They consist of repeating cigar-shape signals, lasting a few minutes and the whole sequence may last up to more than an hour (Fig. 5). An individual block is composed of a sequence of many impulsive signal, as tremors of type 1 , but more closely related in time and with nearly constant amplitude (Fig. 5). Each block is separated from another by a few SDEs with higher amplitudes. The frequency spectrum of a single block has a narrow dominant peak varying between 10 and $30 \mathrm{~Hz}$, depending on the block (Fig. 5). The main differences between both types of tremors lie in the frequency content and mode of occurrence of the events. The fact that tremors of type 2 are observed at one site only might reflect a different source mechanism, site effects or different modes of source excitement.

During the 3 months of experiment in 2011, tremors occur almost all the time at the Central High (2011-OBS04), every 1-3 d to every day, with a quiet period of 1 week at the end of the experiment and no clear periodicity (Fig. 8). The temporal distribution of tremors at 2011-OBS04 is distinct from the other distributions, indicating contrasting dynamics in the tremor generation. In the Central Basin, the occurrence of tremor seem better correlated when considering larger time windows (several hours to day). On 08/05/2011 and 09/06/2011 for instance, long-lasting tremors are recorded on all OBSs deployed in the basin, except 2011-OBS08 and 2011-OBS09, together with a significant increase in the daily rate of SDEs and/or with an increase in the number of tremors during the preceding or following days (Fig. 8). No tremors were recorded on the Western High by the OBSs deployed in 2014, although peaks in the SDEs distributions are observed (Fig. 9). The main source of tremor is located at the northwestern edge of the Western High (2014-OBS08), where the the distribution of tremors highlights three periods of activity lasting a few days and separated by $10-14 \mathrm{~d}$. Few tremors were also recorded north of the Western High at 2011-OBS01 (Fig. 8).

There is a general good correlation between the number of tremors and the number of SDEs recorded at each instrument (Figs 7-9). The sites where most of the tremors are observed are also those producing the highest number of SDEs, except at 2011OBS08 and 2014-OBS01 where only few tremors were recorded. 


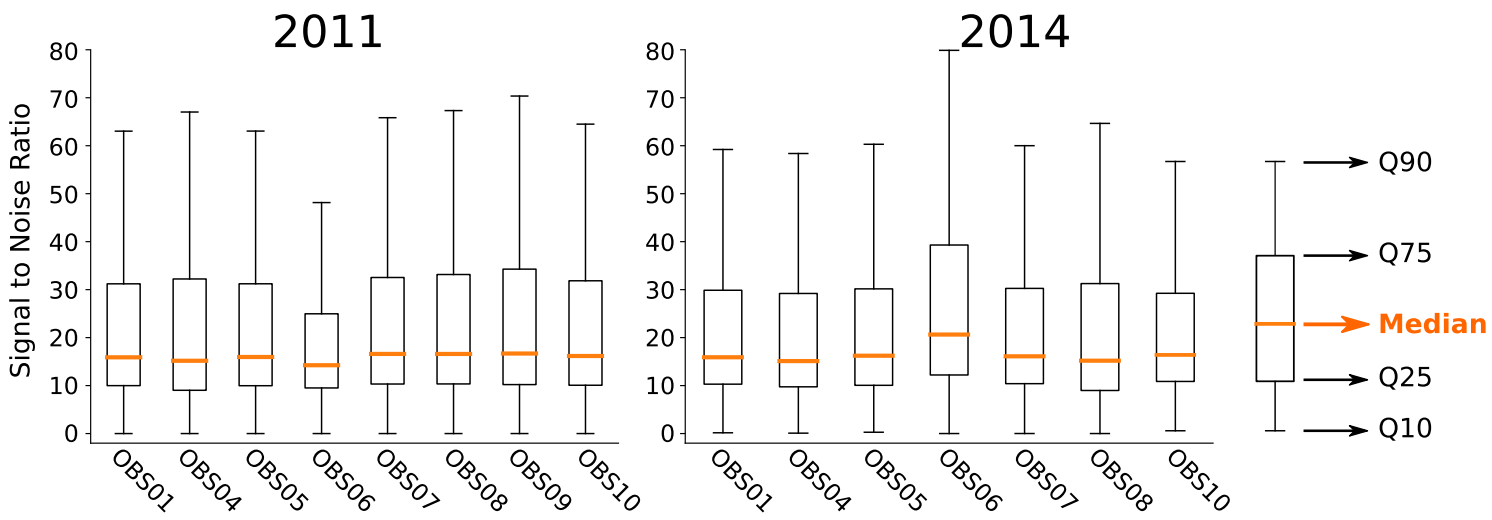

Figure 6. Distribution of the SNR of SDEs detected at each OBS for both networks. The distributions are represented as boxplots; the thicker orange line is the median, the box contains 50 per cent of the distribution around the median (between the 25th and 75th percentiles) and whiskers represent the 10th and 90th percentiles, outliers are not shown.

On the contrary, when the daily rate of SDEs is low, no tremors are detected (e.g. 0BS09 in 2011; OBS05, OBS06 in 2014). In all other cases, the correlation holds and plotting together the SDEs and tremors distribution yield at a possible relationship between both types of signal (Figs 7c, 8 and 9). Indeed, tremors often go along with a high rate of individual SDEs, although peaks in the distributions of individual SDEs are not always accompanied by tremors.

\section{CASE STUDY: THE $M_{\text {w }} 5.1$ EARTHQUAKE，25/07/2011}

On 2011 July 25 , a $M_{\mathrm{w}} 5.1$ earthquake occurred at a depth of 11-14 km under the Western High area (Figs 1 and 2). It was followed by a large sequence of aftershocks, among which many might possibly be linked to gas-related processes, as they were very shallow ( $<2 \mathrm{~km}$; Géli et al. 2018). Approximately $50 \mathrm{~min}$ after the main shock, three atypical signals are recorded on all four components of 2011-OBS01. The seismic amplitude of the signals is strong, similar to the $M_{\mathrm{w}} 5.1$ earthquake, although the signals were not recorded elsewhere, suggesting a very local source, mainly affecting the shallow sediments in the vicinity of the OBS (Fig. 11a). During the first event, the amplitude slowly increases during $\sim 1 \mathrm{~min}$ then suddenly drops to a noisy level (Fig. 11b). At the same time the dominant frequency increases from $\sim 10$ to $25 \mathrm{~Hz}$, then drops. The second event is lower in amplitude and initiated with a sequence of SDEs, similar to a tremor of type 1, with broad-band energy lasting 1-2 min. Then, the dominant frequency smoothly increases to $>40 \mathrm{~Hz}$. The third event had a sharp, high amplitude onset and lasted for $1 \mathrm{hr}$, slowly decreasing in amplitude. The dominant frequency of the signal was steady in time, in the $17-21 \mathrm{~Hz}$ range.

There is a striking correlation between the occurrence of SDEs (clustered and individual events) and the cumulative seismic energy curve at 2011-OBS01, suggesting a relationship between earthquakes and SDEs, at least at this single site (Fig. 8). Indeed, on the 25/07/2011, $2 \mathrm{hr}$ after the earthquake the rate of SDE sharply increases to reach more than 2000 events/d. This high level of activity kept going until the end of the experiment, $5 \mathrm{~d}$ after. On the day of the earthquake, the backazimuths of the SDEs are scattered in all directions, but shortly after, the backazimuths are more clustered around $150^{\circ}$, although with some dispersion (Fig. 10a). What is clear, however, is that there is a lack of sources located in the $50-100^{\circ}$ direction. Interestingly, a few days prior the main shock, the backazimuths of the SDEs shifted from a scattered mode of occurrence to sources located around $150^{\circ}$, suggesting that the same sources of SDEs were activated before and after the earthquake.

\section{DISCUSSION}

\subsection{Nature of the SDEs and tremors}

Non-earthquake short duration signals have long been reported as fish bumps (Buskirk et al. 1981) or mechanical readjustment of the instrument on the sedimentary bottom under its own weight (Ostrovsky 1989). Ifremer recently deployed an experimental device composed of 2 OBSs and a camera off Molene Island (Brest, France) to continuously monitor transient events affecting the seafloor within the framework of the European Multidisciplinary Seafloor and water column Observatory (EMSO) project. The simultaneous camera images and seismic recordings over 2 months revealed that no fish regularly bumped the instruments. More generally, marine fauna directly interacting with the instruments only occurs seldom and produces seismic signals easily distinguishable from SDE (F. Klingelhoefer, personal communication 2018). Worms and shrimps living within the surface sediment layers might also disturb the soft sediments but the image resolution was too low to support this hypothesis.

Long-lasting tremors and SDEs resembling ours were associated with bottom flow agitating the geophones induced by internal tides off Southeast Taiwan (Chang et al. 2016). In that case, tremors were recorded at the natural frequency of the sensors and exhibited a non random periodicity, similar to the M2 tide. Tides are low in the SoM $(1-3 \mathrm{~cm})$ and are not expected to produce strong periodic currents. As a matter of fact, no particular diurnal or semi-diurnal patterns exist in the distribution of SDEs and tremors. Bottom currents in the SoM are in fact mainly driven by climatic and oceanographic conditions (storms, connections with the Black and Mediterranean seas). The few studies of deep current dynamics in the SoM report a current velocity up to $15-20 \mathrm{~cm} \mathrm{~s}^{-1}$ (Besiktepe et al. 1994), which might be strong enough to agitate the OBS sensors, resulting in a tremor-like signal. Thus, current-generated noise is expected to decrease with increasing depth and to be correlated with the presence of canyons or corridors. In 2011, the average number of SDE is generally higher at deeper sites, which contradicts the idea of current-generated signals. Moreover, the relationship between the 


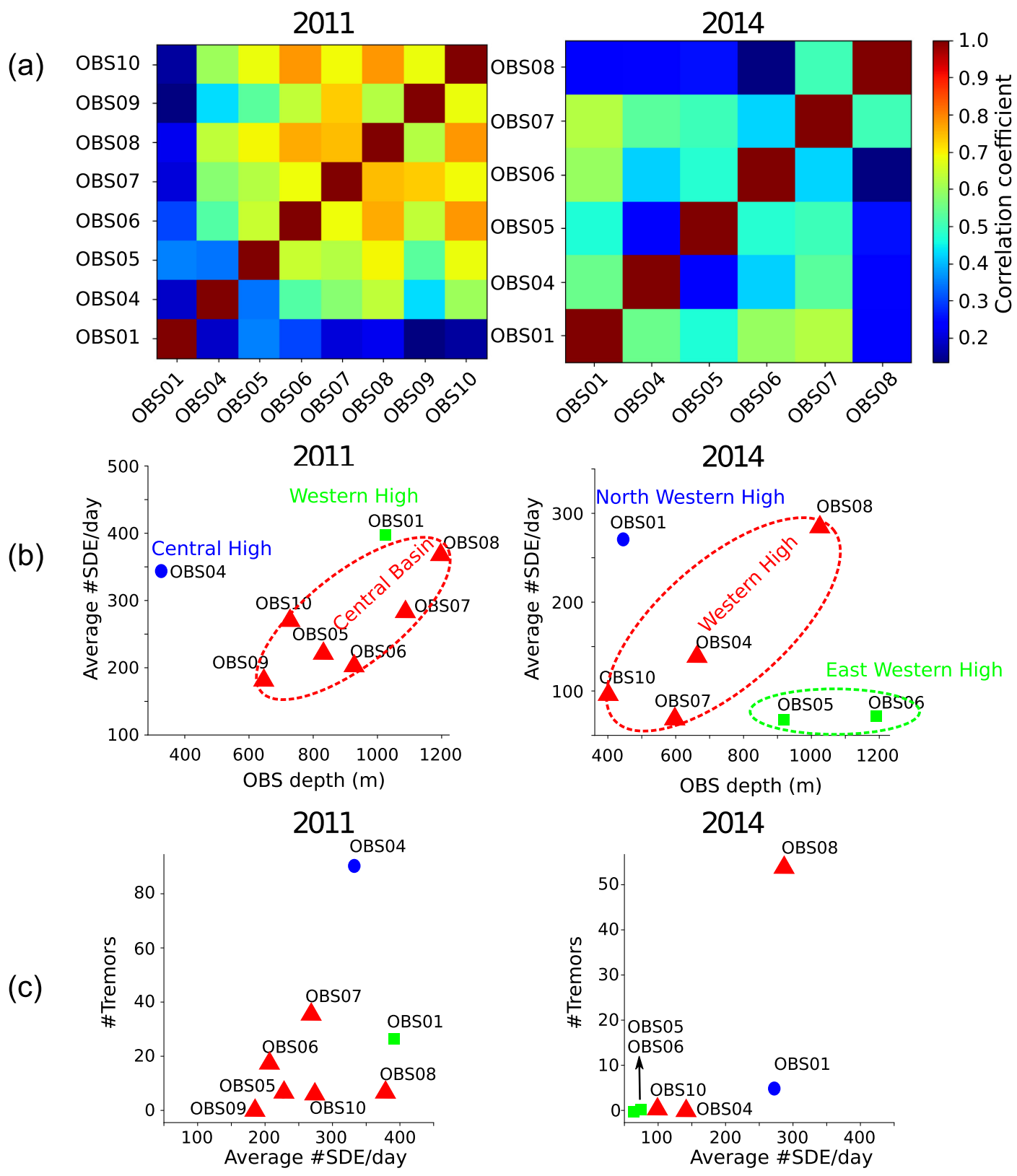

Figure 7. (a) Cross-correlation coefficient of the temporal distributions of SDEs in 2011 (left-hand panel) and 2014 (right-hand panel). The 2014-OBS10 was excluded from this analysis since it only functioned for a month. (b) The average number of SDE/day as a function of the OBS depth in 2011 and 2014 ; regional trends are indicated by the colour and the symbols. (c) The relationship between the number of tremors and the average number of SDE/day in 2011 and 2014; the same regional code is used.

occurrence of tremors and morpho-bathymetric features, such as canyons, is not straightforward. For instance, 2014-OBS04 is located in a wide corridor where strong currents are expected, but no tremors were observed nor a particular high number of SDEs. Moreover, the clear change in the backazimuths of SDEs observed at 2011-OBS01 is also not consistent with current-generated noise. However, currents can not be completely ruled out as possible source of some SDEs (those recorded on the hydrophone for instance) and direct observations from current-metres could resolve this uncertainty.

In the Galicia Margin, Diaz et al. (2007) interpreted long-lasting tremors and SDEs as the resonance of fluid-filled cracks related to hydrothermal circulation, following the model proposed by Chouet (1988) for volcanic tremors and long-period events (LPE). The same mechanism was proposed to explain similar tremors and SDEs in Taiwan (Hsu et al. 2013), the Svalbard Margin (Franek et al. 2017) or the SoM (Tary et al. 2012; Bayracki et al. 2014; Embriaco et al. 2014). In all these cases, the fluid-filled crack model was well supported by evidence of cold seeps, increased methane concentration or temperature variations at the bottom, indicating gas seepage out of the seafloor. As a matter of fact, there are many similarities between the signals reported here and volcanic tremors and LPEs. Tremors can be considered as the random superimposition of wave groups resulting from a set of several sources or a random source 

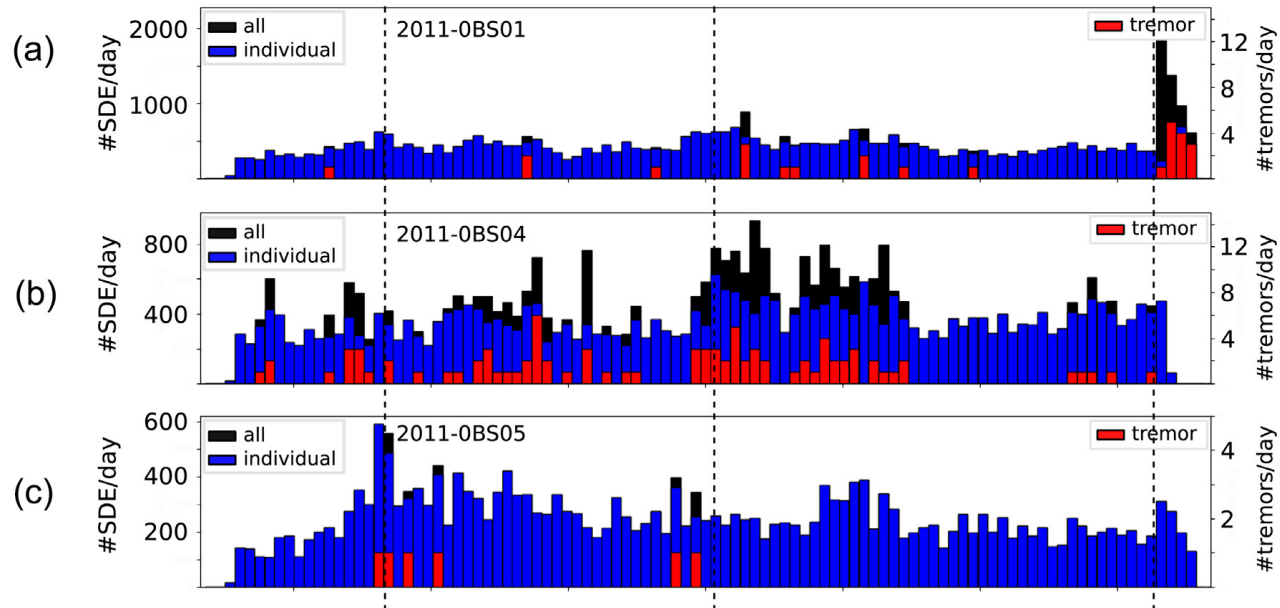

(d)

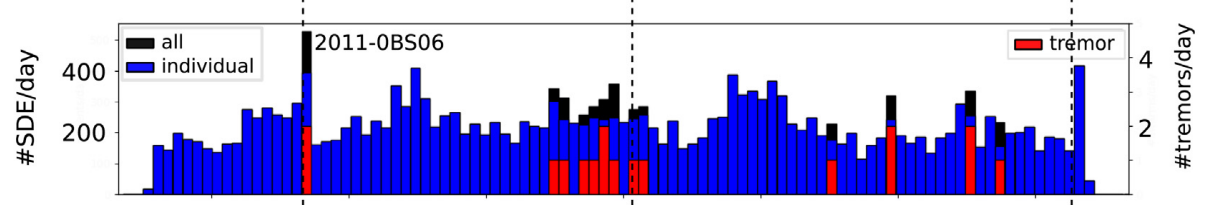

(e)

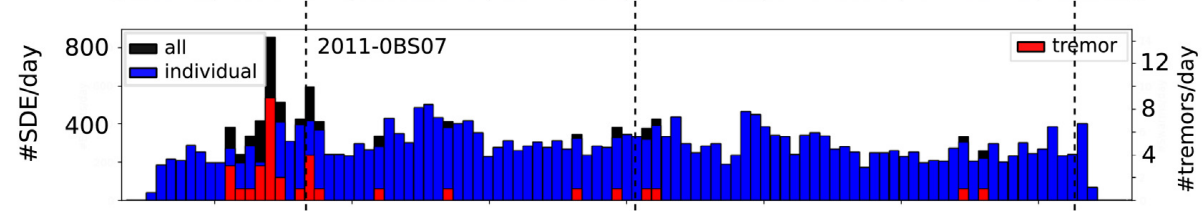

(f)

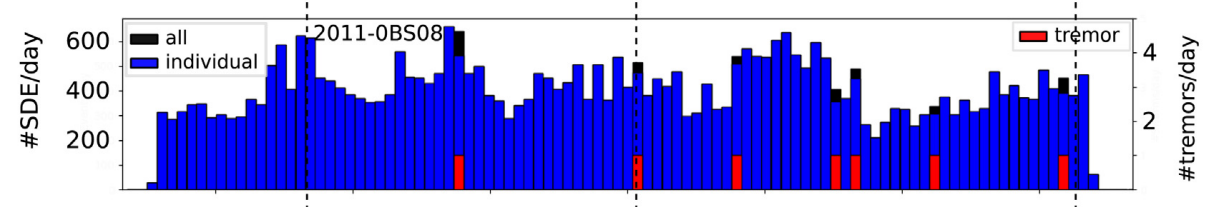

(g)

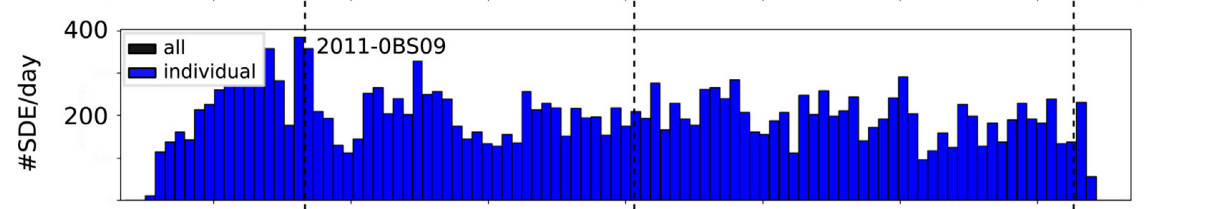

(h)

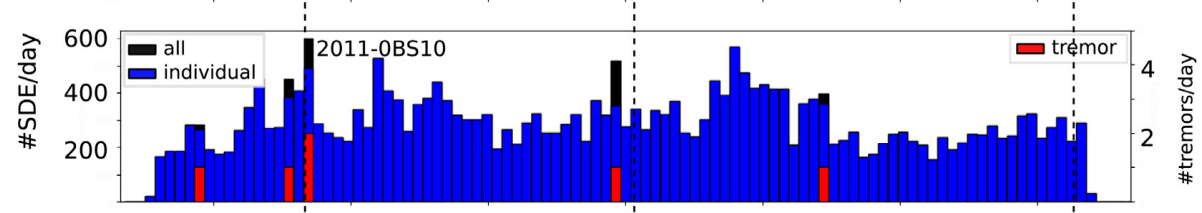

(i)

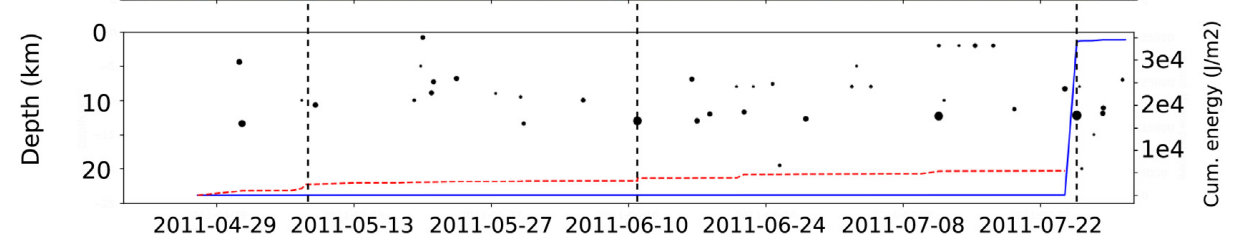

Figure 8. (a-h) Temporal distribution individual SDEs (blue), tremors and all types of events (black) in 2011. Note that the number of tremors does not reflect their duration. (i) Black dots represent the regional seismicity in time and depth; the magnitude of the earthquakes is represented by the size of the symbols. The blue solid curve is the cumulative energy received by the array derived as $\mathrm{Er}=\mathrm{E}_{0} / \mathrm{d}^{2}$; with $\log \left(\mathrm{E}_{0}\right)=1.5 * M_{\mathrm{w}}+11.8$ (e.g. Stein \& Wysession 2003$)$ and $d$ the distance to the centre of the network. The red dotted line is the cumulative $E_{r} * 100$ for earthquakes occurring before the $25 / 07 / 2011$. Vertical dotted line indicate the strongest earthquakes.

(Seidl et al. 1990). In volcanic contexts, they are considered as random time-series with a multipeak frequency spectrum. The dominant frequency may also increase during an intensified eruptive episode as the conduits widen (or the volume of the source decreases; Chouet 1988; Chouet, 1996). The phenomenon is clearly observed at 2011-OBS01 in response to a strong ground motion (Fig. 11) but also during some shorter tremors, where the dominant frequency is shifted up to $30-50 \mathrm{~Hz}$ (Fig. 10). In the resonant crack model, tremors thus reflect sustained pressure variations, for example due to a fluctuating flow indicating fluid migration, while SDEs reflect random transients in the local pressure field, for example due to readjustment in the local strain. In this framework, we propose that tremors might indicate that gas is migrating out of the seafloor. SDEs and tremors recorded by OBSs in a gas-rich setting could 
(a)

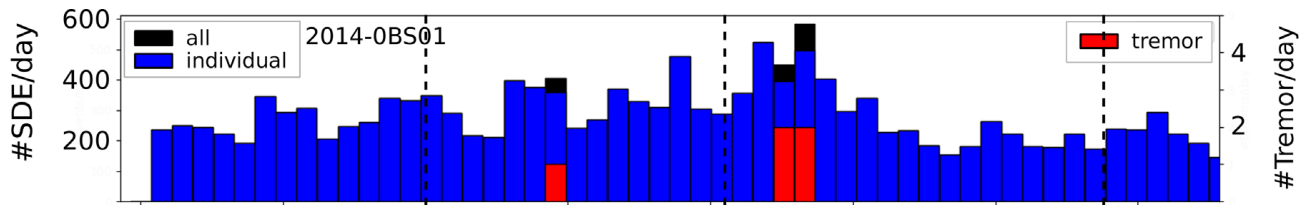

(b)

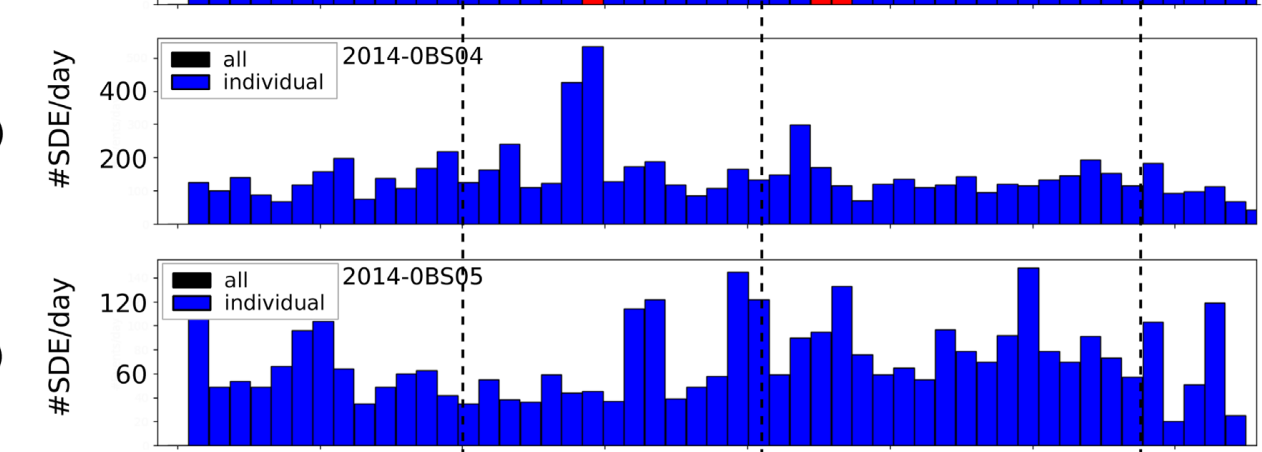

(c)

(d)

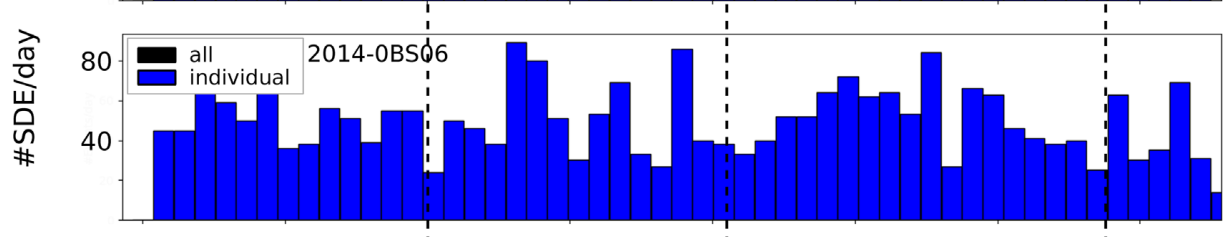

(e)

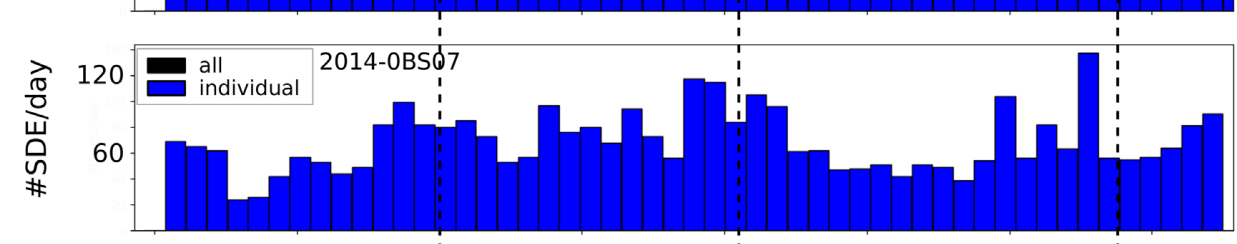

(f)

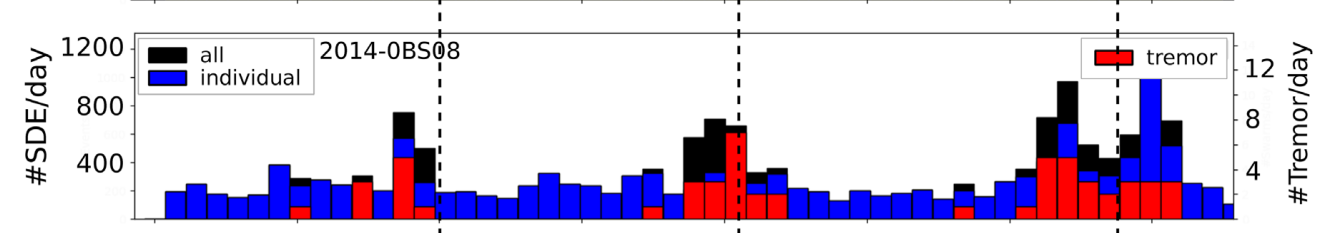

(g)

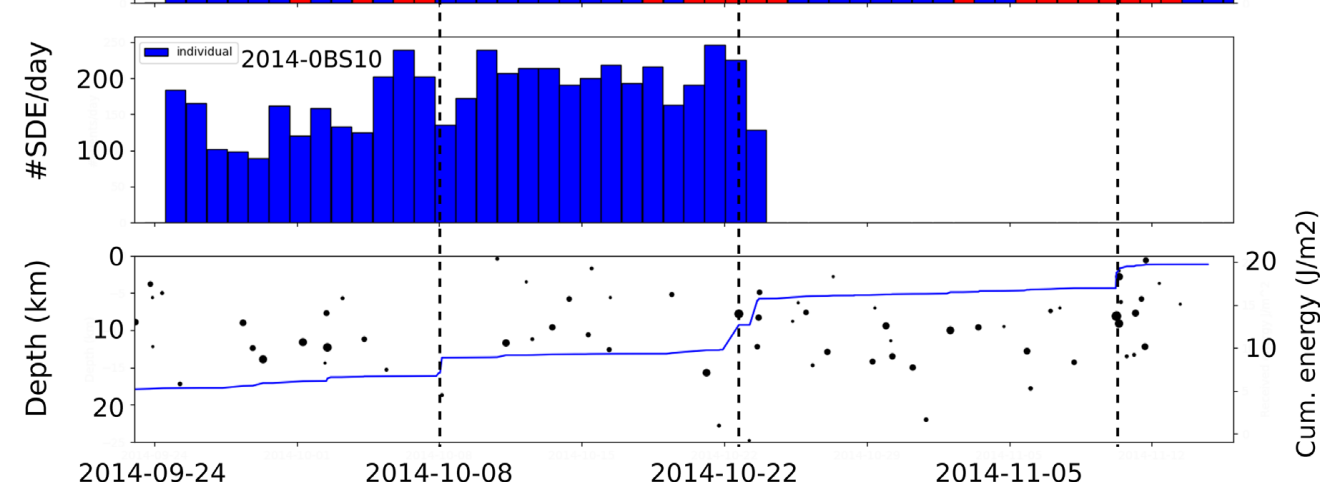

Figure 9. (a-g) Temporal distribution individual SDEs (blue), tremors (red) and all type of events (black) in 2014. (h) Black dot represents the regional seismicity in time and depth; the magnitude of the earthquakes is represented by the size of the symbols. The blue curve is the cumulative energy received by the array define as in Fig. 8. Vertical dotted lines indicate the strongest earthquakes.

thus be a useful tool to monitor gas activity as already proposed by Franek et al. (2017).

\subsection{Spatiotemporal dynamics of gas-related processes in the SoM}

There is a clear spatial variability in the distribution of SDEs and tremors therefore in the presumed gas-related dynamics. Unfortunately, a direct comparison between the acoustic-located flares and the SDEs is hardly possible for two reasons: (1) the SDEs are supposed to represent local perturbations in the direct vicinity of the OBS but the acoustic flares located in 2009 (Marmesonet expedition; Dupré et al. 2015; Fig. 12) represent zones of gas emission rather than point sources; thus they provide much lesser resolution than OBS observations; (2) the uncertainties of the backazimuths estimates are difficult to assess and the absolute directions are probably not fully reliable; temporal trends in the backazimuths are however not affected. 


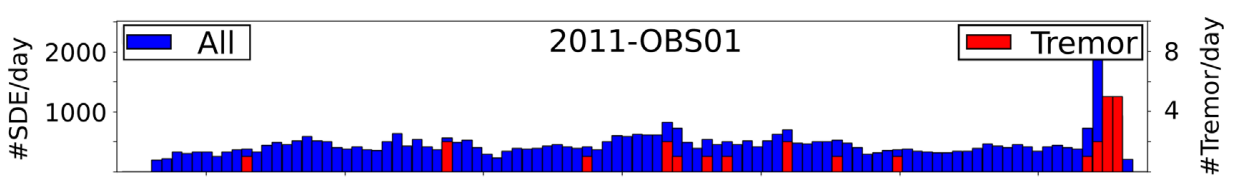

(a)

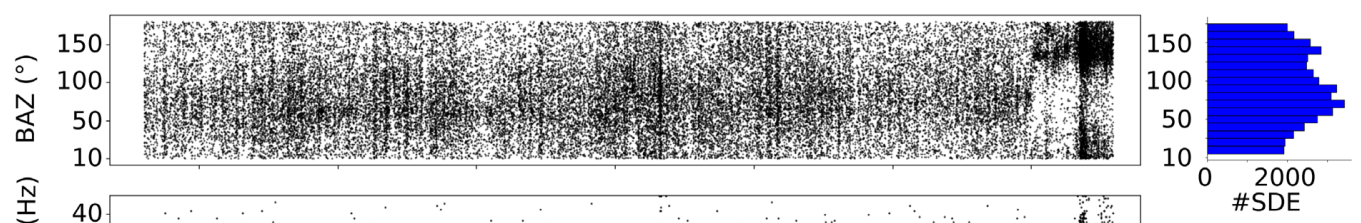

(b)
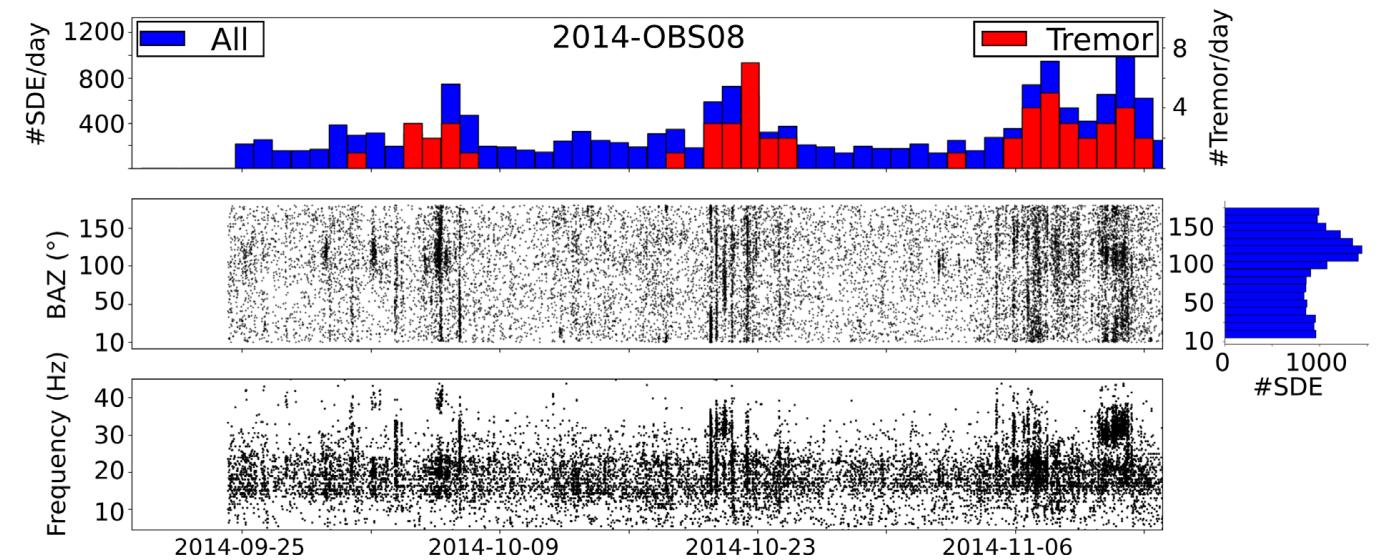

Figure 10. From top to bottom: temporal distribution of SDEs (blue) and tremors (red), temporal distribution of the associated backazimuths and the dominant frequency of each event for (a) 2011-OBS01 and (b) 2014-OBS08.

The most active site in 2011 is located on the top of the Central High, a $600 \mathrm{~m}$ high anticline separating the Central and Cinarcik Basins. Numerous gas escapes were observed on the top of the circular structure during the 2009 Marmesonet expedition (Dupré et al. 2015), as the anticline is highly fractured (Imren et al. 2001; Carton et al. 2007), providing pathways for free gas migration along the $\mathrm{E}-\mathrm{W}$ trending fractures. Acoustic observations from a $\mathrm{BOB}$ module also revealed numerous gas seeps on the top of the Central High, one of them most possibly just below 2011-OBS04 (Bayrakci et al. 2014), where a continuous gas seep was also previously identified. As the BOB module monitored the OBS sector for only 2 cycles, no direct comparison is possible between the tremor and fluid flow rate derived from echograms (Leblond et al. 2014). The OBS data suggest that the gas flare was continuously active during the first 2.5 months of the experiment and then experienced a quiet phase until the end of the experiment. There was no correlation between the SDE/tremor distribution at the Central High and other areas, suggesting uncorrelated gas sources and/or different triggering factors.

In the Central Basin, the SDE and tremor activity is comparatively moderate and a possible relationship with the acoustic flares is less obvious. However, in this region, the OBSs located in areas where no acoustic flares were observed in 2009 are those having the lowest rate of SDE and tremors, although the contrary is not systematically true. As already mentioned, there is a good temporal correlation between the distributions of SDEs suggesting that the gas sources could be connected or that there is a triggering factor impacting the whole basin. As a matter of fact, the average daily rate of SDE is generally higher for deeper sites within the basin in 2011, that is thicker water column, than shallower ones, making both hypotheses possible (Fig. 7b). In 2014, a similar relationship is less trivial. Nevertheless, when considering only the four stations located on the top of the Western High, the average daily rate of SDEs increases with depth as well (Fig. 7b), although the temporal distributions of SDEs are poorly correlated (Fig. 7a). In 2014, the study area was shifted to the west and at a smaller scale, which might imply different oceanographic conditions and thus the lack of consistency between both networks.

The 2011-OBS01 was deployed just $1 \mathrm{~km}$ northwest of the Western High, in the Tekirdag Basin. The daily rate of SDE is high during the whole experiment, with a moderate tremor activity though. On the 25/07/2011, just after the $M_{\mathrm{w}} 5.1$ earthquake, the tremor activity significantly increases, while the instrument was sitting near a modest acoustic flare (Fig. 12). In addition, atypical, long-lasting signals resembling volcanic tremors were recorded by the OBS 50 min after the main shock. As discussed in the following section, it is possible that the strong ground motion triggered cracks opening and gas emission in the vicinity of 2011-OBS01. In 2014, the 2014-OBS08 was located just $1 \mathrm{~km}$ south of 2011-OBS01 and was found to be the most active site during the experiment. Numerous gas flares were also reported in this area and possibly related to a gas-filled structure resembling a buried mud volcano (Dupré et al. 2015; Fig. 12). The presence of this structure with respect to 2011-OBS01 and 2014-OBS08 could explain the high SDE activity there and the fact that only 2011-OBS01 reacted to the $M_{\mathrm{w}} 5.1$ earthquake. 


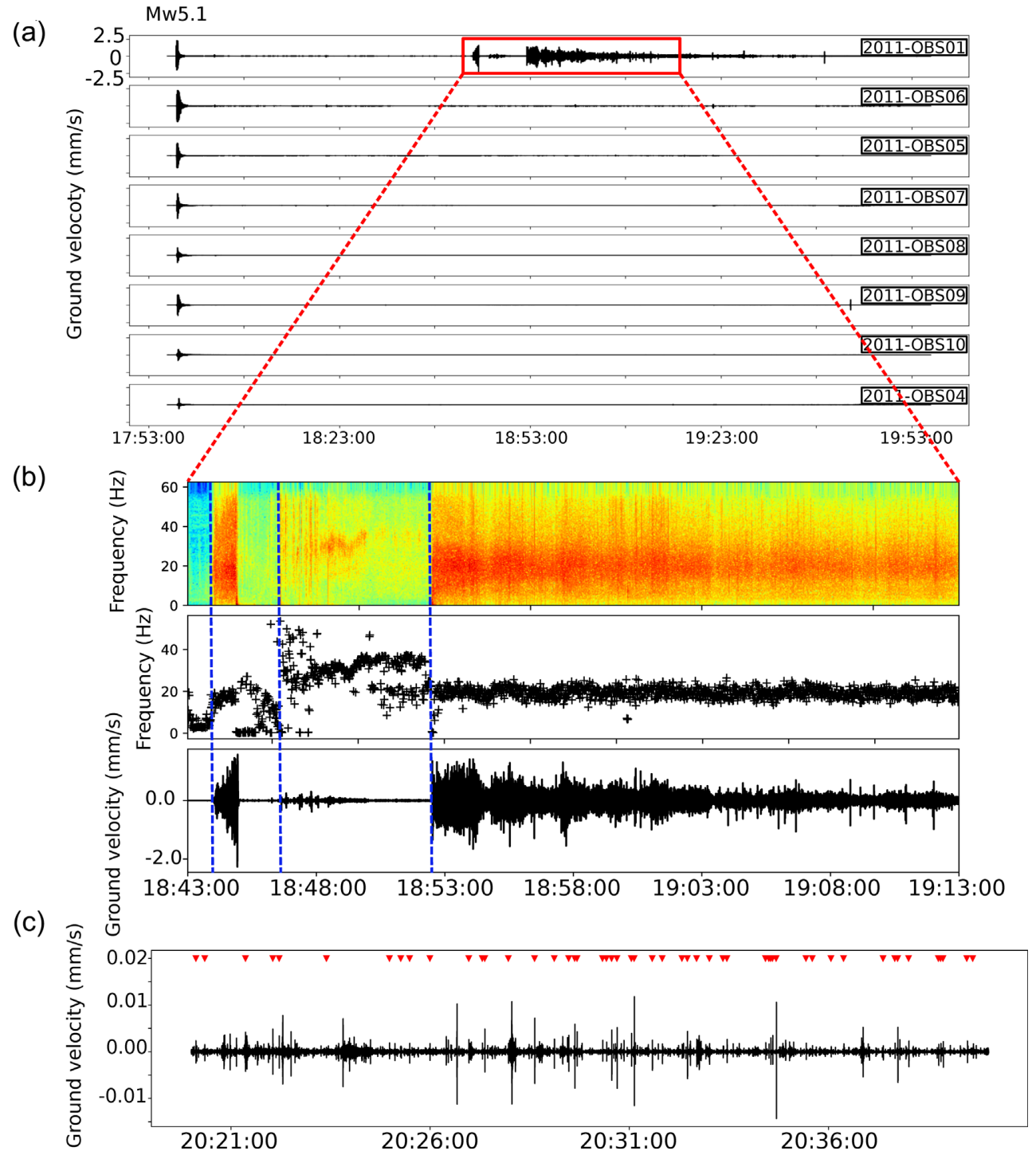

Figure 11. (a) Vertical component seismograms of the $M_{\mathrm{w}} 5.1$ earthquake on 25/07/2011 for all OBSs. The seismograms are sorted by epicentral distance (Fig. 2) and the ground velocity scale is the same for all seismograms. (b) A close up on the long-lasting tremor recorded on 2011-OBS01. The normalized spectrogram, dominant frequency of each spectrum in the spectrogram and the seismogram. The vertical dotted lines indicate the onset of the three atypical signals. (c) 20 min of signal occurring $2 \mathrm{hr} 20$ after the main shock showing the high rate of SDEs.

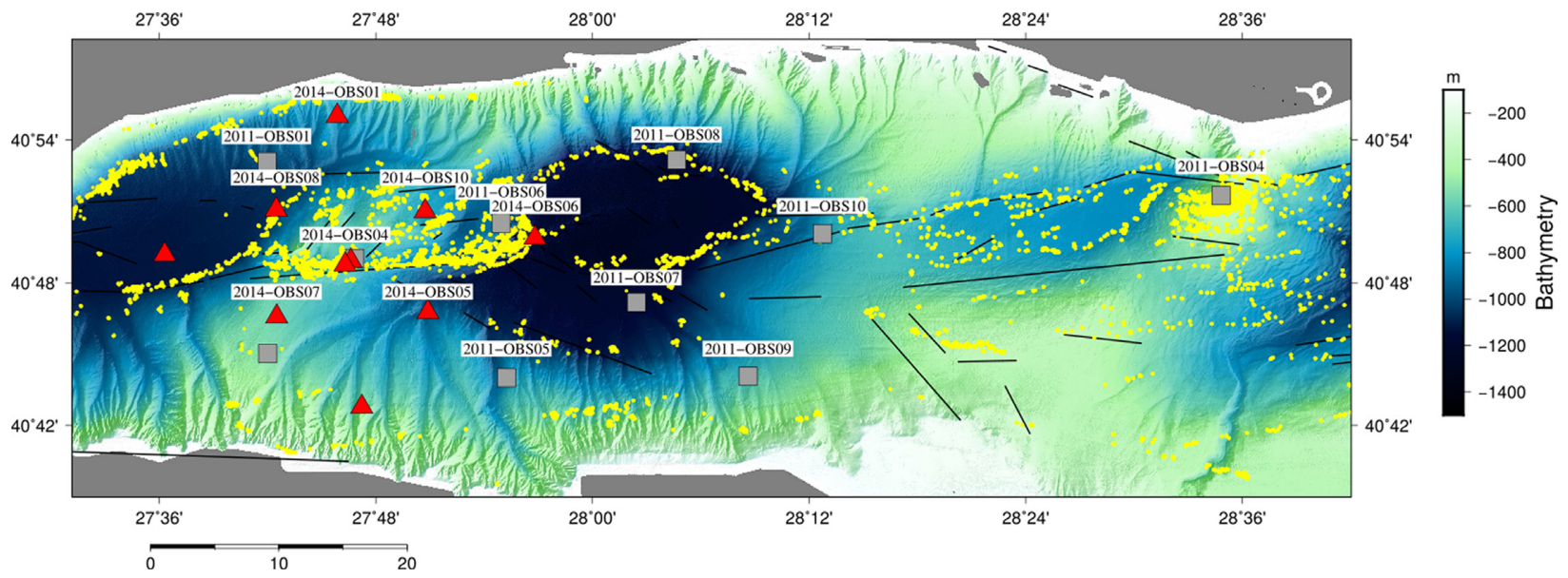

Figure 12. Location of the acoustic flares observed during the Marmesonet expedition in 2009 (Dupre et al. 2015) in the western SoM. Here the yellow dots represent areas of gas emission rather than an exact point source location. The OBSs and faults are indicated as on Fig. 1. 
Although numerous acoustic gas flares were observed along the southern edge of the Western High, the region was poorly active in terms of SDEs/tremors, suggesting that no significant gas emission occurred, except for a brief episode in May at 2014-OBS04.

\subsection{Gas migration triggering}

\subsubsection{Seismicity}

The causal relationship between earthquakes and gas emission has been postulated in several studies but is complex and not systematic. Strong earthquakes $(M>7)$ might create pathways for free gas to migrate by fracturing the sediments, like in the Arabian Sea (Fischer et al. 2013) or in the Gulf of Izmit (Kuscu et al. 2005). However, no such phenomena was observed in long-term data in the Svalbard Margin (Franek et al. 2017) nor offshore Vancouver Island (Römer et al. 2016), where ground motion was weaker. This lack of consistency between gas emission and earthquake can be explained by magnitudes too small to induce gas mobilization (Lapham et al. 2013) or site effects induced by the seismic energy radiation pattern (Römer et al. 2016).

Our data reveal a possible relationship between earthquakes and gas migration. Indeed, when considering the seismic energy received on the OBS network (i.e. seismic energy per unit area) rather than the absolute energy, it appears that some earthquakes might have impacted the gas dynamics in the SoM. During the 2011 experiment, the highest amount of seismic energy is radiated by the 25/07/2011 earthquake (Fig. 8), located $9 \mathrm{~km}$ from OBS01 and followed by a sequence of numerous aftershocks (Géli et al. 2018). Three atypical tremors were also observed, followed by a significant increase in the SDEs rate that lasted for several days until the end of the experiment (Figs 8, 10 and 11). There is a striking similarity between the received seismic energy curve and the SDE/tremor distribution of 2011-OBS01 (Fig. 8), suggesting that the local strong ground motion did trigger gas migration in the vicinity of 2011-OBS01. The occurrence of the atypical signals could be a coincidence, since not recorded elsewhere, although they resemble some volcanic tremors. Thus, they might reflect conduits opening as the free gas migrates upward through a disturbed stress field. An increase in the number of individual SDEs was also noted at 2011-OBS06 and at 2011-OBS05 but no tremors were detected indicating a possible site effect at 2011-OBS01, either due to the nature of the sediments, the radiation pattern in the seismic energy, or the proximity to the epicentre. Unfortunately, 2011-OBS02, located near the epicentre stopped recording before the earthquake so the latest hypothesis could no be verified. Another possibility would be that the 2011-OBS01 site was connected to a specific, independent gas source. We note that $5 \mathrm{~d}$ prior the main shock, the direction of the SDE sources suddenly changed from a general scattered mode to a focused mode around $150^{\circ}$, so a change in the SDE sources was already initiated at 2011-OBS01.

A local earthquake occurring on $08 / 05 / 2011$ is the second strongest shock on the array. On the same day, peaks in the distributions of SDEs are observed at all OBSs (Fig. 6), sometimes accompanied by tremors, except at 2011-OBS4. A few days prior to the main shock, the tremor activity was significant at 2011-OBS07 and the daily rate of SDE was increasing at the other OBSs until the $07 / 05 / 2011,1 \mathrm{~d}$ before the earthquake. The transient increase in the overall $\mathrm{SDE} /$ tremor rate might be triggered by the earthquake, although the ground motion was weak. In comparison, the 25/07/2011 earthquake, much more energetic, impacted only 2 or 3 sites, whereas located a few kilometres to the east. Another scenario would be that the gas flux was already fluctuating over the whole area, as suggested by the overall increase in the SDE rate; and was amplified by the earthquake.

In 2014, there are three main jumps in the cumulative seismic energy received at the OBS network, although not comparable to the $25 / 07 / 2011$ earthquake (Fig. 9). At first order, there is also a remarkable similarity between the cumulative received energy and the tremor distribution at 2014-OBS08: the three main earthquakes roughly correspond to the three periods of tremor activity. On $08 / 10 / 2014$, the $M 3$ earthquake is not directly followed by a particular SDE/tremor activity although a high tremor activity was already initiated at 2014-OBS08 for $2 \mathrm{~d}$. On 23/10 and 25/10, local earthquakes coincide with a long lasting tremor crisis, initiated on $20 / 10$, with a peak activity on $23 / 10$. Finally, the last locally strong ground motion occurred on $11 / 11 / 2014$, during a persistent tremor episode. The tremors sequence reached two peaks on $08 / 11$ and $12 / 11$, suggesting that the second peak might have been triggered by the earthquake. In all three cases, earthquakes did not directly trigger SDE/tremor activity, although they might act as catalysts for long-lasting sequences. The 2014-OBS08 is located just a few kilometres from 2011-OBS01, where a striking relationship was observed between the seismic energy and potential gas released. Thus, it is possible that the area is prone to seismically triggered gas emission, due to its connection to the deeper/remote gas source or the nature of the sediments. As for the apparent time shift between the tremor crisis and the main shocks, no relationship with seismic precursors was observed so the initiation of gas migration does not seem to be directly triggered by earthquakes.

\subsubsection{Water-level oscillations}

In the open sea, recurrence and intensity of gas emission are in good agreement with the lunar tidal cycle (Boles et al. 2001; Hsu et al. 2013; Römer et al. 2016). Indeed, a drop in the hydrostatic pressure yields a decrease in the total load of the gas bubble. When the internal bubble pressure exceeds both the total load and the sediment resistance to fracturing, the bubble rises through pre-existing cracks (Boudreau 2012) toward the surface. In the SoM, tides are low in amplitude and generally consist of mixed but mainly diurnal tides in the order of a few centimetres (Yüce 1993). Besides, no diurnal periodicity is observed in the distribution of SDEsover the whole study area. Long-period oscillations (2-14 d) of the sea level have also been observed and are mainly due to internal gravity waves, river flow inputs or local winds (Yüce \& Alpar 1997; Alpar \& Yüce 1998). Our data only report a few months, a time period too short to discuss these long-term variations. Nevertheless, the number of SDE globally depends on the OBS depth in the Central Basin, suggesting that the water height might play a role in the SDE generation. A similar but less obvious relationship might be derived from the 2014 observations. Dominant periods in the SDEs daily rate were estimated from periodograms of the distributions, considered as time-series. A significant period of $14-15 \mathrm{~d}$ was found for several sites in 2011 and 2014 (Table 2), in good agreement with the typical long-period oscillations observed in the SoM. Longer observations are however needed to better constrain the effect of the water level on the SDE generation and gas dynamics.

\section{CONCLUSION}

This study reports the existence of two types of SDE and tremor in the SoM from OBS data recorded in 2011 and 2014. The frequency content, location and mode of occurrence of both types of signal 
Table 2. First significant periods estimated from the periodogram of the SDE daily rate in time at each OBS.

\begin{tabular}{|c|c|}
\hline OBS & Dominant periods $(\mathrm{d})$ \\
\hline 2011-OBS01 & $35-21-15$ \\
\hline 2011-OBS04 & $35-1-15$ \\
\hline 2011-OBS05 & $50-15$ \\
\hline 2011-OBS06 & 15 \\
\hline 2011-OBS07 & $20-13-1$ \\
\hline 2011-OBS08 & $26-15$ \\
\hline 2011-OBS09 & $52-21$ \\
\hline 2011-OBS10 & $26-15$ \\
\hline 2014-OBS01 & $14-9-6$ \\
\hline 2014-OBS04 & $14-8-6$ \\
\hline 2014-OBS05 & $18-5-7$ \\
\hline 2014-OBS06 & $14-8-4.5$ \\
\hline 2014-OBS07 & 18-9-6 \\
\hline 2014-OBS08 & $18-10-7$ \\
\hline
\end{tabular}

are in good agreement with the fluid-filled crack model, usually proposed to explain volcanic LPEs and tremors. In the case of the SoM, tremors are thus likely to reflect sustained gas migration, such as gas emission, whereas SDEs would result from transients in the local pressure field within the cracks. OBS recordings of atypical signals could thus be used to monitor gas flares, when located in the vicinity of the instrument.

Although the relationship between earthquakes and gas migration is not systematic; locally strong earthquakes might disturb the shallowest layers of sediments by opening conduits for free gas migration. Strong directional site effects are observed for earthquaketriggered gas migration, either due to the mechanical properties of the sediments, the proximity of the source of gas or the connection with the source of gas. However the initiation of gas migration is not systematically triggered by earthquakes. At the basin scale, water-level oscillations might also affect the local stress field responsible for the SDE generation. A better understanding of the SDE and tremor generation, for example through source modelling and multiparameters observations and experimentation, would help quantifying gas-related process and, in particular, the emitted volumetric flow in the water column. Long term, continuous recordings, for example stretching over at least a year, would also constrain the long-term trends in the temporal behaviour of SDEs and tremors and in the associated gas-related processes.

\section{ACKNOWLEDGEMENTS}

This work was supported by the MAREGAMI ANR-TUBITAK Collaborative project (grant ANR-16-CE03-0010). The OBS data were collected within two EU-funded Research Programmes, for example the ESONET Network of Excellence (contract $n^{\circ}$ 036851) and the MARSITE Integrated Project (contract $n^{\circ}$ 308417). JeanFrançois Rolin and Roland Person, coordinators of ESONET, as well as Nurcan Özel, coordinator of MARSITE are warmly acknowledged. The OBS data are accessible at http://doi.org/10.17882/497 64 (for the 2011 data set) and at http://doi.org/10.17882/49656 (for the 2014 data set). Careful reviews from three anonymous reviewers improved this paper.

\section{REFER EN CES}

Allen, R., 1982. Automatic phase pickers: their present use and future prospects, Bull. seism. Soc. Am., 72, S225-S242.
Alpar, B. \& Yüce, H., 1998. Sea-level variations and their interactions between the Black Sea and the Aegean Sea, Estuarine Coastal Shelf Sci., 46, 609-619.

Batsi, B. et al., 2018. An alternative view of the microseismicity along the western main marmara fault, Bull. seism. Soc. Am., 108, 2650-2674.

Bayrakci, G. et al., 2014. Acoustic monitoring of gas emissions from the seafloor. Part II: a case study from the Sea of Marmara, Mar. Geophys. Res., 35, 211-229.

Beyreuther, M., Barsch, R., Krischer, L., Megies, T., Behr, Y. \& Wassermann, J., 2010. ObsPy: a Python toolbox for seismology, Seism. Res. Lett., 81, 530-533.

Beşiktepe, Ş.T., Sur, H.I., Özsoy, E., Latif, M.A., Oğuz, T. \& Ünlüata, Ü., 1994. The circulation and hydrography of the Marmara Sea. Prog. Oceanogr., 34, 285-334.

Bohnhoff, M., Wollin, C., Domigall, D., Küperkoch, L., Martínez-Garzón, P., Kwiatek, G., Dresen, G. \& Malin, P.E., 2017. Repeating Marmara Sea earthquakes: indication for fault creep, Geophys. J. Int., 210, 332-339.

Bohnhoff, M., Bulut, F., Dresen, G., Malin, P.E., Eken, T. \& Aktar, M., 2013. An earthquake gap south of Istanbul, Nat. Commun., 4, 1999.

Boles, J.R., Clark, J.F., Leifer, I. \& Washburn, L., 2001. Temporal variation in natural methane seep rate due to tides, Coal Oil Point area, California, J. geophys. Res., 106, 27077-27086.

Boudreau, B.P., 2012. The physics of bubbles in surficial, soft, cohesive sediments, Mar. Pet. Geol., 38, 1-18.

Bourry, C. et al., 2009. Free gas and gas hydrates from the Sea of Marmara, Turkey Chemical and structural characterization, Chem. Geol., 264, 197206.

Buskirk, R.E., Frohlich, C., Latham, G.V., Chen, A.T. \& Lawton, J., 1981. Evidence that biological activity affects ocean bottom seismograph recordings, Mar. Geophys. Res., 5, 189-205.

Carton, H. et al., 2007. Seismic imaging of the three-dimensional architecture of the Çınarcık basin along the North Anatolian fault, J. geophys. Res.: Solid Earth, 112, B06101.

Chang, E.T.Y., Chao, B.F., Chen, G.-Y. \& Liau, J.-M., 2016. Internal tides recorded at ocean bottom off the coast of Southeast Taiwan, J. geophys. Res. Oceans, 121, 3381-3394.

Chouet, B., 1988. Resonance of a fluid-driven crack: radiation properties and implications for the source of long-period events and harmonic tremor, $J$. geophys. Res. Solid Earth, 93, 4375-4400.

Chouet, B.A., 1996. Long-period volcano seismicity: its source and use in eruption forecasting, Nature, 380, 309.

Doran, A.K. \& Laske, G., 2017. Ocean-Bottom seismometer instrument orientations via automated Rayleigh-wave arrival-angle measurements, Bull. seism. Soc. Am., 107, 691-708.

Dupré, S. et al., 2015. Tectonic and sedimentary controls on widespread gas emissions in the Sea of Marmara: results from systematic, shipborne multibeam echo sounder water column imaging, J. geophys. Res.: Solid Earth, 120, 2891-2912.

Diaz, J., Gallart, J. \& Gaspà, O., 2007. Atypical seismic signals at the Galicia Margin, North Atlantic Ocean, related to the resonance of subsurface fluid-filled cracks, Tectonophysics, 433, 1-13

Embriaco, D. et al., 2014. Monitoring of gas and seismic energy release by multiparametric benthic observatory along the North Anatolian Fault in the Sea of Marmara (NW Turkey), Geophys. J. Int., 196, 850-866.

Ergintav, S. et al., 2014. Istanbul's earthquake hot spots: geodetic constraints on strain accumulation along faults in the Marmara seismic gap, Geophys. Res. Lett., 41, 5783-5788.

Fischer, D., Mogollón, J. M., Strasser, M., Pape, T., Bohrmann, G., Fekete, N., Spiess, V. \& Kasten, S., 2013. Subduction zone earthquake as potential trigger of submarine hydrocarbon seepage, Nat. Geosci., 6, 647.

Franek, P., Plaza-Faverola, A., Mienert, J., Buenz, S., Ferré, B. \& Hubbard, A., 2017. Microseismicity linked to gas migration and leakage on the Western Svalbard Shelf, Geochem., Geophys., Geosyst., 18, 4623-4645.

Greinert, J., 2008. Monitoring temporal variability of bubble release at seeps: the hydroacoustic swath system GasQuant, J. geophys. Res., 113, C07048.

Géli, L. et al., 2008. Gas emissions and active tectonics within the submerged section of the North Anatolian Fault zone in the Sea of Marmara, Earth planet. Sci. Lett., 274, 34-39. 
Geli, L. et al., 2018. Gas and seismicity within the Istanbul seismic gap, Sci. Rep., 8, 6819.

Gower, J. \& Ross, G., 1969. Minimum spanning trees and single linkage cluster analysis, J. R. Stat. Soc. Ser. C (Appl. Stat.), 18, 54-64.

Hsu, S.K., Wang, S.Y., Liao, Y.C., Yang, T.F., Jan, S., Lin, J.Y. \& Chen, S.C., 2013. Tide-modulated gas emissions and tremors off SW Taiwan, Earth planet. Sci. Lett., 369, 98-107.

Imren, C., Le Pichon, X., Rangin, C., Demirbağ, E., Ecevitoğlu, B. \& Görür, N., 2001. The North Anatolian Fault within the Sea of Marmara: a new interpretation based on multi-channel seismic and multi-beam bathymetry data, Earth planet. Sci. Lett., 186, 143-158.

Kuşçu, I., Okamura, M., Matsuoka, H., Gökaşan, E., Awata, Y., Tur, H., Şimşek, M. \& Keçer, M., 2005. Seafloor gas seeps and sediment failures triggered by the August 17, 1999 earthquake in the Eastern part of the Gulf of Izmit, Sea of Marmara, NW Turkey, Mar. Geol., 215, 193-214.

Konstantinou, K.I. \& Schlindwein, V., 2003. Nature, wavefield properties and source mechanism of volcanic tremor: a review, J. Volc. Geotherm. Res., 119, 161-187.

Lapham, L., Wilson, R., Riedel, M., Paull, C.K. \& Holmes, E.M., 2013. Temporal variability of in situ methane concentrations in gas hydrate-bearing sediments near bullseye vent, northern Cascadia margin, Geochem. Geophys. Geosyst., 14, 2445-2459.

Leblond, I., Scalabrin, C. \& Berger, L., 2014. Acoustic monitoring of gas emissions from the seafloor. Part I: quantifying the volumetric flow of bubbles, Mar. Geophys. Res., 35, 191-210.

Niu, F. \& Li, J., 2011. Component azimuths of the CEArray stations estimated from P-wave particle motion, Earthq. Sci., 24, 3-13.

Ostrovsky, A.A., 1989. On the nature of microshocks recorded by ocean bottom seismographs, Mar. geophys. Res., 11, 113-118.

Römer, M., Riedel, M., Scherwath, M., Heesemann, M. \& Spence, G.D., 2016. Tidally controlled gas bubble emissions: a comprehensive study using long-term monitoring data from the NEPTUNE cabled observatory offshore Vancouver Island, Geochem., Geophys., Geosyst., 17, 37973814.

Ruffine, L. et al., 2012. Geochemical dynamics of the natural-gas hydrate system in the Sea of Marmara, offshore Turkey, in Geochemical Dynamics of the Natural-Gas Hydrate System in the Sea of Marmara, Offshore Turkey, in Advances in Natural Gas Technology, pp. 29-56, ed. Al-Megren, H., InTechOpen.
Scholz, J.R., Barruol, G., Fontaine, F.R., Sigloch, K., Crawford, W. \& Deen, M., 2017. Orienting Ocean-Bottom Seismometers from P-wave and Rayleigh wave polarisations, Geophys. J. Int., 208, 1277-1289.

Schneider von Deimling, J., Brockhoff, J. \& Greinert, J., 2007. Flare imaging with multibeam systems: data processing for bubble detection at seeps, Geochem. Geophys. Geosyst., 8, Q06004.

Seidl, D., Kirbani, S.B. \& Brüstle, W., 1990. Maximum entropy spectral analysis of volcanic tremor using data from Etna (Sicily) and Merapi (central Java), Bull. Volcanol., 52, 460-470.

Sohn, R.A., Hildebrand, J.A., Webb, S.C. \& Fox, C.G., 1995. Hydrothermal micro-seismicity at the megaplume site on the southern juan de fuca ridge, Bull. seism. Soc. Am., 85, 775 .

Stachnik, J.C., Sheehan, A.F., Zietlow, D.W., Yang, Z., Collins, J. \& Ferris, A., 2012. Determination of New Zealand ocean bottom seismometer orientation via Rayleigh-wave polarization, Seism. Res. Lett., 83, 704 713.

Stein, S. \& Wysession, M., 2003. An Introduction to Seismology, Earthquakes and Earth Structure, pp. 273, Blackwell.

Tary, J.B., Geli, L., Guennou, C., Henry, P., Sultan, N., Çağatay, N. \& Vidal, V., 2012. Microevents produced by gas migration and expulsion at the seabed: a study based on sea bottom recordings from the Sea of Marmara, Geophys. J. Int., 190, 993-1007.

Wang, X., Chen, Q., Li, J. \& Wei, S., 2016. Seismic sensor misorientation measurement using p-wave particle motion: an application to the necsaids array, Seism. Res. Lett., 87, 901-911.

Withers, M., Aster, R., Young, C., Beiriger, J, Harris, M., Moore, S. \& Trujillo, J., 1998. A comparison of select trigger algorithms for automated global seismic phase and event detection, Bull. seism. Soc. Am., 88, 95106

Yüce, H. \& Alpar, B., 1997. Subtidal sea-level variations in the Sea of Marmara, their interactions with neighboring seas and relations to wind forcing, J. Coastal Res., 1086-1092.

Yüce, H., 1993. Water-level variations in the Sea of Marmara, Oceanol. Acta, 16, 335-340.

Zha, Y., Webb, S.C. \& Menke, W., 2013. Determining the orientations of ocean bottom seismometers using ambient noise correlation, Geophys. Res. Lett., 40, 3585-3590. 